
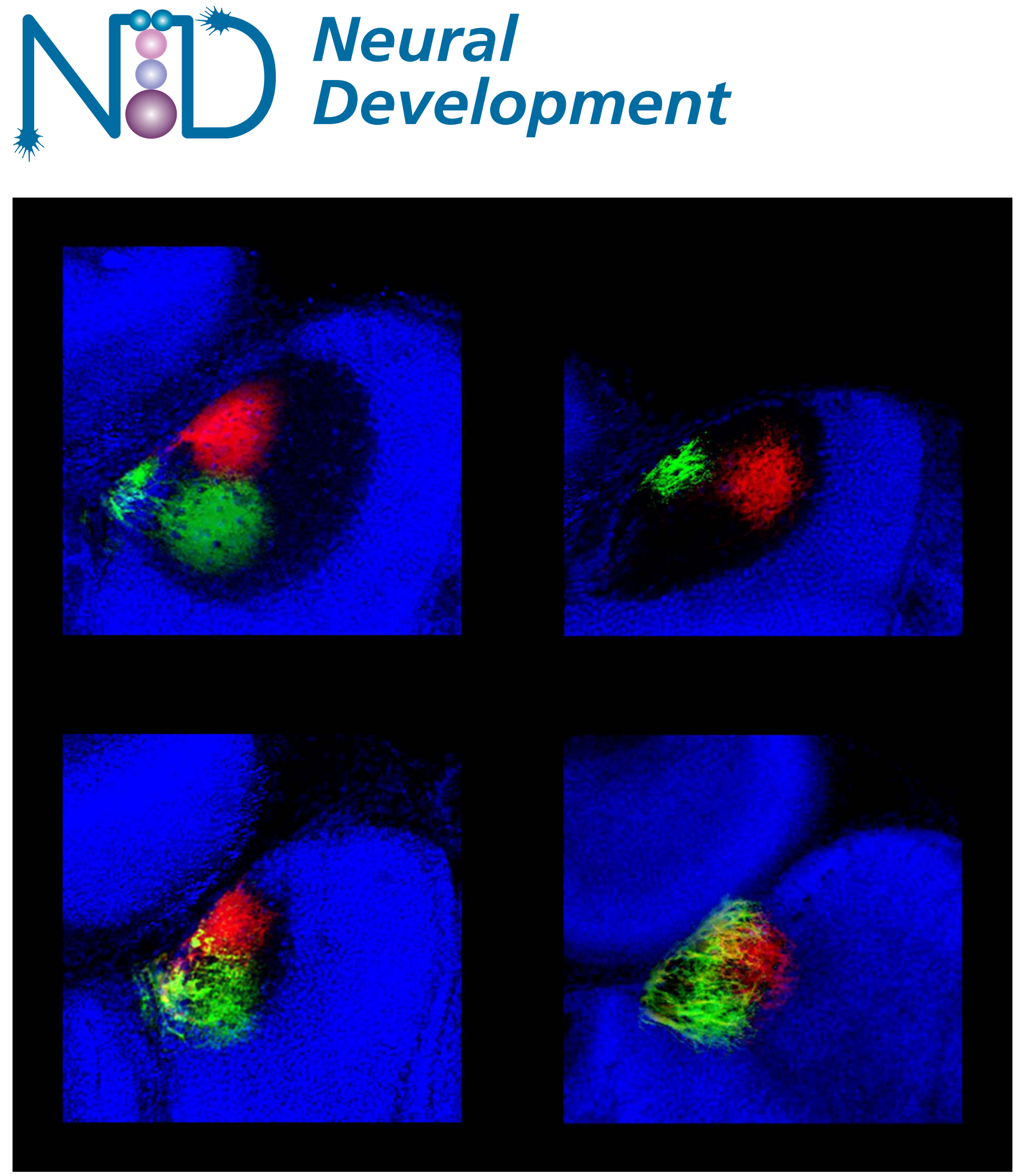

Meis1 specifies positional information in the retina and tectum to organize the zebrafish visual system

Erickson et al.

C Biomed Central

Erickson et al. Neural Development 2010, 5:22

http://www.neuraldevelopment.com/content/5/1/22 (18 June 2010) 


\title{
Meis1 specifies positional information in the retina and tectum to organize the zebrafish visual system
}

\author{
Timothy Erickson ${ }^{1}$, Curtis R French", Andrew J Waskiewicz ${ }^{1,2,3^{*}}$
}

\begin{abstract}
Background: During visual system development, multiple signalling pathways cooperate to specify axial polarity within the retina and optic tectum. This information is required for the topographic mapping of retinal ganglion cell axons on the tectum. Meis1 is a TALE-class homeodomain transcription factor known to specify anteriorposterior identity in the hindbrain, but its role in visual system patterning has not been investigated.

Results: meis 1 is expressed in both the presumptive retina and tectum. An analysis of retinal patterning reveals that Meis1 is required to correctly specify both dorsal-ventral and nasal-temporal identity in the zebrafish retina. Meis1-knockdown results in a loss of smad1 expression and an upregulation in follistatin expression, thereby causing lower levels of Bmp signalling and a partial ventralization of the retina. Additionally, Meis1-deficient embryos exhibit ectopic Fgf signalling in the developing retina and a corresponding loss of temporal identity. Meis1 also positively regulates ephrin gene expression in the tectum. Consistent with these patterning phenotypes, a knockdown of Meis1 ultimately results in retinotectal mapping defects.

Conclusions: In this work we describe a novel role for Meis1 in regulating Bmp signalling and in specifying temporal identity in the retina. By patterning both the retina and tectum, Meis 1 plays an important role in establishing the retinotectal map and organizing the visual system.
\end{abstract}

\section{Background}

In order to preserve the spatial coordinates of visual input, retinal ganglion cell (RGC) axons are topographically organized in the visual processing centres of the midbrain. Retinotopic mapping has been most extensively studied in the optic tectum of fish, amphibians, and chick, and in the superior colliculus of mice. Within both the retina and the tectum, axially restricted expression of the Eph and Ephrin families of axon guidance molecules provides some of the positional information required for retinotectal map formation. Interactions between Eph receptor tyrosine kinases and their cognate Ephrin ligands result in cytoskeletal rearrangements and changes in cell adhesion, thereby eliciting either repulsive or attractive responses. By interpreting the molecular Eph and Ephrin code, RGC axons form a precisely

\footnotetext{
*Correspondence: aw@ualberta.ca

'Department of Biological Sciences, University of Alberta, CW405, Biological Sciences Bldg, Edmonton T6G 2E9, Canada

Full list of author information is available at the end of the article
}

ordered arrangement within the optic tectum that accurately reflects their axial position within the retina $[1,2]$.

Axial patterning of the retina is required to establish the correct domains of Eph and Ephrin expression. During eye development, retinal patterning occurs along both the dorsal-ventral (DV) and nasal-temporal (NT) axes $[3,4]$. The DV axis is established through an antagonistic relationship between the Bone morphogenetic protein $(\mathrm{Bmp})$ and Hedgehog signalling pathways. In the dorsal retina, Smad-dependent Bmp/Growth differentiation factor (Gdf) signalling initiates expression of the dorsal-specific T-box transcription factors $t b \times 5$ and $t b x 2 b$, which in turn activate ephrinB expression [5-8]. Additionally, Wnt signalling is required to maintain dorsal identity $[9,10]$. In the ventral retina, Hedgehog signals from the ventral midline induce the expression of Vax homeodomain transcription factors [11-13], thereby establishing ventral ephB expression [14-17]. Restricted ephrinB and ephB expression along the DV axis is 
required for normal formation of the retinotectal map $[18,19]$.

The NT axis is defined by the restricted expression of forkhead transcription factors foxG1 (bf1) and foxD1 $(b f 2)$ in the nasal and temporal retina, respectively [20-22]. These factors function antagonistically to promote the expression of ephrinA ligands in the nasal retina and a subset of ephA receptors in the temporal domain. Altering the normal domains of ephrinA and ephA expression causes defects in retinotectal map formation [23-25]. Similarly to the DV axis, secreted signalling proteins are also involved in NT patterning. Fibroblast growth factor (Fgf) signals from the telencephalon and periocular mesenchyme promote nasal (ephrinA) and repress temporal fates (ephA) [26-28]. At this time, it is not clear whether temporal identity represents a retinal ground state or if it is induced by an unidentified factor.

Axial patterning of the tectum/superior colliculus is also a critical component of proper retinotectal map formation. In the midbrain, eph and ephrin genes are expressed in opposing gradients. EphrinA ligands are expressed in a posterior to anterior gradient, while EphA receptors are expressed in an opposing anterior to posterior gradient [29]. Likewise, along the mediallateral axis, EphrinB ligands tend to be expressed in a medial to lateral gradient while EphB receptors exhibit an opposing lateral to medial gradient [19]. These opposing gradients, together with the repulsive interactions between Eph-Ephrin molecules, suggested a gradient matching model of retinotectal map formation [30]. This model is supported by experiments showing that, for example, EphA3-expressing temporal RGCs tend not to innervate posterior regions of the tectum expressing high levels of EphrinA ligands [31,32]. However, this model does not explain all facets of retinotectal map formation, and other factors such as attractive EphEphrin interactions, axon competition [33], and other molecular cues may refine the process [30]. It is clear, however, that the precise topographic mapping of RGCs onto the tectum/superior colliculus is a highly regulated process in which Eph and Ephrin interactions play a key role.

Eph and Ephrin interactions have been well studied in the hindbrain, where they are involved in cell sorting and restricting cell movements between rhombomeres [34-36]. Of particular importance in regulating hindbrain eph and ephrin expression are the TALE-class homeodomain transcription factors Meis/Pknox and $\mathrm{Pbx}$, which act in trimeric complexes with Hox proteins to impart segmental identity to the hindbrain rhombomeres [37-41]. However, Pbx and Meis also perform Hox-independent roles in eye, lens, midbrain, heart and muscle development [42-46].
Meis1 is a particularly attractive candidate for playing an important role in patterning the visual system. meis 1 expression in the developing eye and midbrain is conserved across multiple species, and Meis1-deficiency causes microphthalmia in mice, chickens and zebrafish [47-49]. The Drosophila Meis homolog Homothorax (Hth) also plays an important role in insect eye development $[50,51]$. Structurally, Meis proteins contain a Pbxinteraction domain in the amino terminus, a DNA-binding homeodomain and a carboxy-terminal activation domain [52]. In addition to the trimeric Meis-Pbx-Hox complexes that regulate hindbrain patterning, Meis proteins can form heterodimeric complexes with $\mathrm{Pbx}$ and with a subset of posterior Hox proteins $[53,54]$. Meis and its binding partners have been identified as important regulators of eph and ephrin gene expression in the midbrain and hindbrain through both direct and indirect mechanisms [37,44, 55-59]. However, despite this well-characterized role in hindbrain axial patterning and the regulation of eph and ephrin gene expression, the function of Meis1 in axial patterning of the retina and in the formation of the retinotectal map has not been fully addressed.

In this study, we use morpholino-mediated knockdown of Meis1 protein in zebrafish to determine if Meis1 patterns the retinotectal system. In the DV axis, Meis1 promotes ocular Bmp signalling through the positive regulation of smad1 expression and the negative regulation of follistatin a $(f s t a)$. With regard to NT patterning, Meis1 knockdown causes a loss of temporal identity in the retina. This phenotype can be attributed to an increase in retinal Fgf signalling and a decrease in foxd 1 expression in the temporal retina. We also demonstrate that Meis1 positively regulates ephrin gene expression in the tectum. Consistent with these patterning defects, Meis1-depleted embryos also exhibit retinotectal mapping defects in both the NT and DV axes. We conclude that Meis1 contributes to retinotectal map formation by specifying positional information in both the retina and tectum.

\section{Results}

\section{meis1 expression and morpholino knockdown}

Zebrafish meis1 is expressed in the presumptive eye, midbrain and hindbrain regions between 11 and 15 hours post-fertilization (hpf; Figure 1A-F) [38]. A transverse section through the optic vesicle of a $13 \mathrm{hpf}$ embryo stained by a Meis1 monoclonal antibody reveals the presence of Meis1 protein in both the dorsal and ventral leaflets of the eye (Figure 1D). At $15 \mathrm{hpf}$, meis $1 \mathrm{mRNA}$ is expressed in the dorsal midbrain that will go on to form the optic tectum (Figure 1F). At $20 \mathrm{hpf}$, Meis1 protein is present in the retinal progenitor cells, in the presumptive tectum, and in the hindbrain (Figure 1G). By $50 \mathrm{hpf}$, the early pattern of meis 1 mRNA expression has changed 

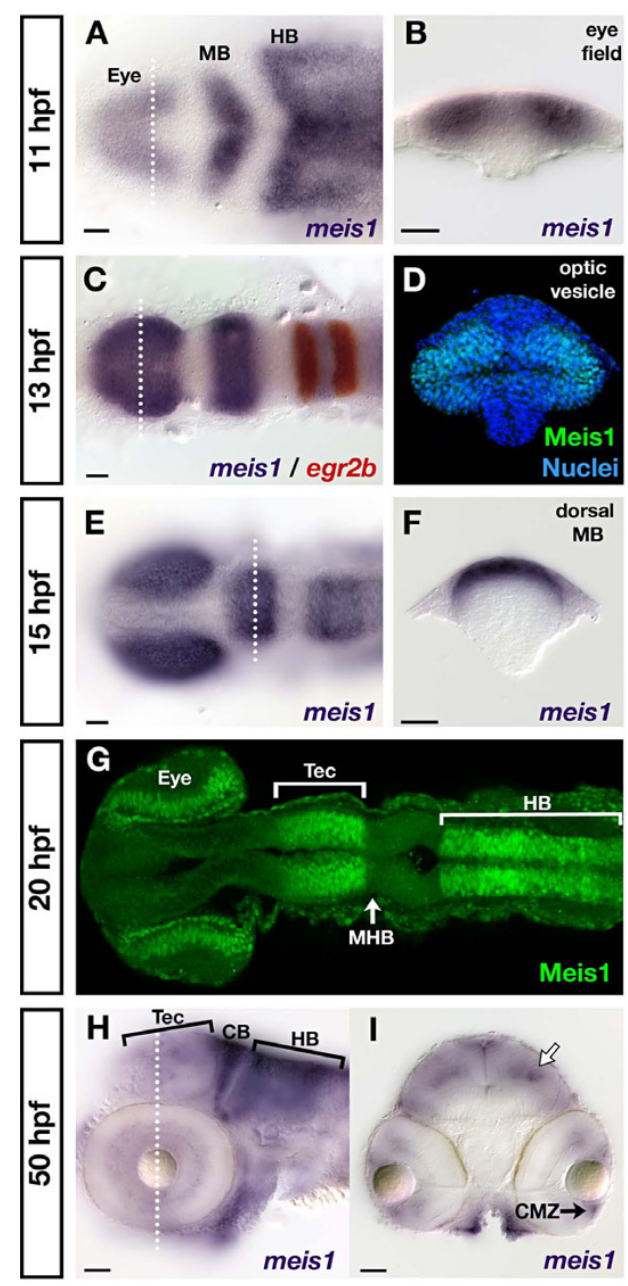

Figure 1 Developmental time course of meis 1 mRNA and protein expression. (A, B) mRNA in situ hybridizations (ISHs) for meis1 at $11 \mathrm{hpf}$ showing expression in the eye field, and in the presumptive midbrain (MB) and hindbrain (HB). The transverse section (B) shows meis 1 expression in the eye field. (C) mRNA ISH showing meis 1 expression at $13 \mathrm{hpf}$ in the optic vesicles, midbrain and hindbrain. egr2b/krox20 expression (red) marks rhombomeres 3 and 5 of the hindbrain. (D) Transverse section of a whole mount immunostain for Meis1 showing protein in the dorsal and ventral leaflets of the $13 \mathrm{hpf}$ optic vesicle. Hoechst 33258 stain marks the nuclei. (E, F) mRNA ISH at 15 hpf showing continued expression of meis 1 in the optic vesicles, midbrain and hindbrain. The transverse section (F) shows meis1 expression in the dorsal midbrain. (G) Whole mount immunostain for Meis1 protein at $20 \mathrm{hpf}$. Meis1 protein is present in the eye, presumptive tectum (Tec), and in the hindbrain (HB) up to the r1-r2 boundary. Meis1 is excluded from the midbrain-hindbrain boundary (MHB). (H, I) mRNA ISH at $50 \mathrm{hpf}$ showing meis1 expression in the hindbrain (HB) and cerebellum (CB) and tectum (Tec). The transverse section (I) shows meis 1 expression in the ciliary marginal zone (CMZ) of the retina and in the dorsal midline and a deeper layer of the tectum (white arrow). Embryos in $(A, C, E, G)$ are shown in dorsal view with anterior to the left. Embryo in $(H)$ is shown in lateral view with anterior to the left. Transverse sections in $(B, D, F, I)$ are oriented dorsal up. The dotted lines in $(A, C, E, H)$ indicate the position of the corresponding transverse sections in $(B, D, F, I)$. All scale bars $=50 \mu \mathrm{m}$. dramatically. meis 1 is robustly expressed in the hindbrain and cerebellum (Figure $1 \mathrm{H}$ ), but its tectal expression has retreated to the dorsal midline and to a deeper layer of the tectum (Figure 1I). In the retina, meis 1 expression is largely restricted to the ciliary marginal zone (CMZ; Figure 1I). The robust expression of meis1 in the eye and tectum at early developmental stages (10 to $20 \mathrm{hpf}$ ) suggests that Meis1 may be playing an early role in patterning the zebrafish visual system.

To examine the function of Meis1 in eye and midbrain development, we used an ATG-targeted translation-blocking morpholino to knock down Meis1 protein expression [44]. This morpholino was used in all experiments unless otherwise noted. To determine the effectiveness of this morpholino, we compared the levels of Meis1 protein between $16 \mathrm{hpf}$ wild-type and meis1 morphant embryos by whole-mount immunohistochemistry using a monoclonal antibody against zebrafish Meis1 (Additional file 1A, B). In meis1 morphant embryos, the specific Meis1 signal is lost, showing that the morpholino effectively reduces Meis1 protein levels. We also observe a similar knockdown of Meis1 protein using a second, non-overlapping translation blocking morpholino (meis1NOL; Additional file 1C, D). Furthermore, meis $1 \mathrm{NOL}$ gives similar retinal patterning phenotypes to the ATG morpholino (Additional file 1E-H). Together, these results suggest that the meis1 morpholino represents an accurate Meis1 loss of function model.

\section{Meis1 knockdown results in downregulation of ephrin gene expression in the tectum}

Axial patterning of the tectum is an important element in retinotectal map formation. Precise patterns of eph and ephrin expression within the tectum establish positional cues that, together with the eph and ephrin genes expressed in the retina, instruct the innervation patterns of the RGC axons. Since Meis1 is expressed in the developing tectum, and Meis proteins have been shown to regulate eph and ephrin expression in the midbrain $[56,57,59]$, we tested whether zebrafish Meis1 also plays a critical role in tectal patterning by examining the expression of ephrin genes. In 32 hpf embryos, ephrin $A 2$ (efna2), efna3b, efna $a$ and $e f n b 3 b$ are all expressed in the presumptive tectum, with the ephrinA genes also being expressed in a DV domain at the midbrain-hindbrain boundary and cerebellum (Figure 2A, C, E, G). In meis1 morphants, the tectal expression of efna2 $(n=11 /$ $11)$, efna3b $(n=13 / 13)$, efna5a $(n=57 / 57)$, and efnb3b $(n=12 / 14)$ are reduced (Figure 2B, D, F, H). These defects in ephrin gene expression are not due to failings in midbrain-hindbrain boundary formation as $f g f 8 a$ $(n=35 / 35)$, eng $2 a(n=31 / 31)$, and pax2a $(n=18 / 18)$ expression at the midbrain-hindbrain boundary is normal in meis1 morphants (Additional file 2). Together, 


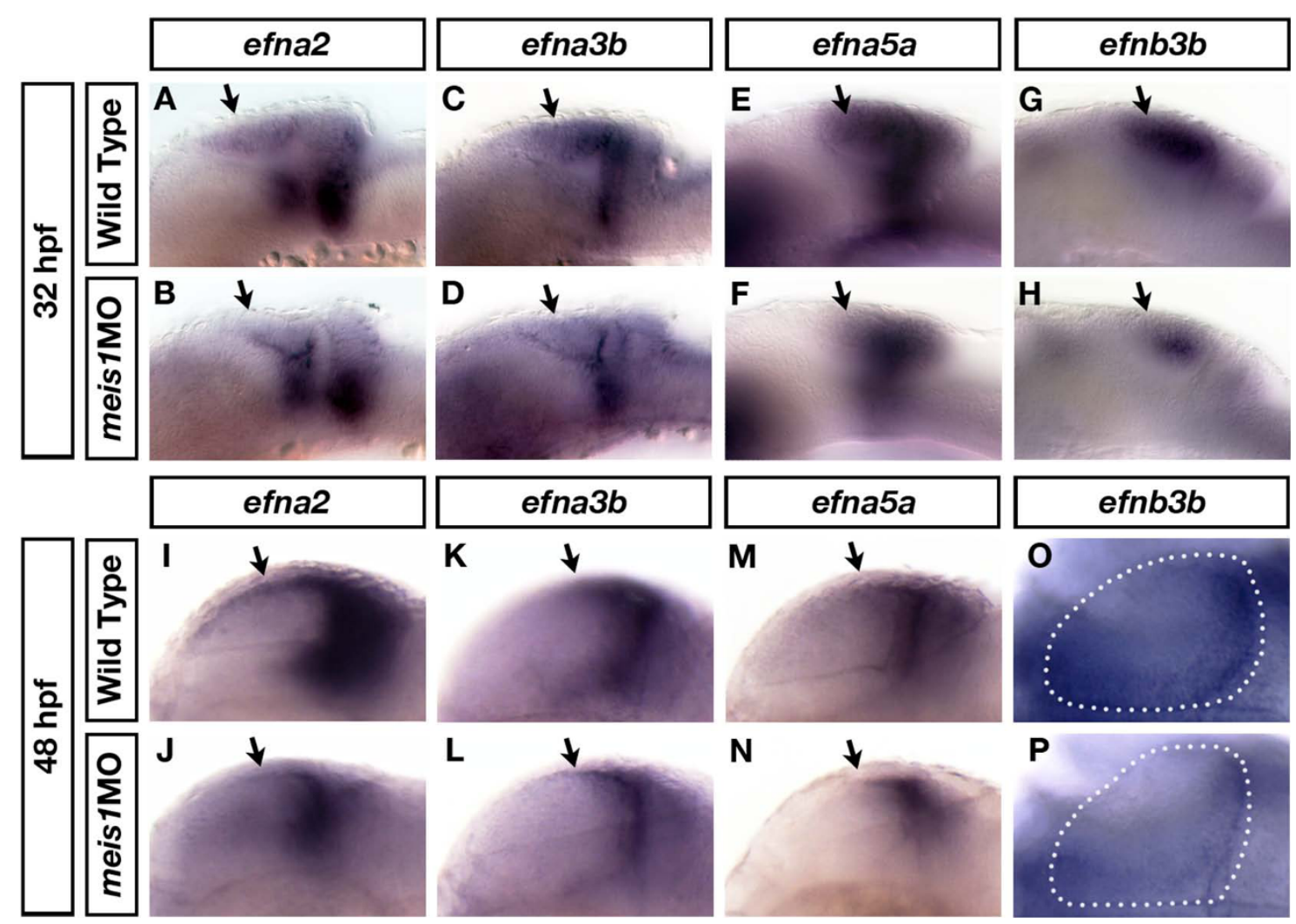

Figure 2 Meis1 positively regulates ephrin gene expression in the tectum. (A-H) mRNA in situ hybridizations (ISHs) for efna2 (A, B), efna3b $(C, D)$, efna5a ( $E, F)$ and efnb3b $(G, H)$ in 32-hpf wild-type $(A, C, E, G)$ and meis1 morphant (meis $1 M O)(B, D, F, H)$ embryos. Meis1 knockdown leads to a downregulation in the tectal expression of these ephrin genes (arrows) (I-P) mRNA ISH for efna2 (I, J), efna3b (K, L), efna5a (M, N) and efnb3b $(\mathrm{O}, \mathrm{P})$ in 48-hpf wild-type $(I, K, \mathrm{M}, \mathrm{O})$ and meis 1 morphant $(\mathrm{J}, \mathrm{L}, \mathrm{N}, \mathrm{P})$ embryos. The early defects in tectal ephrin gene expression remain in 48-hpf meis1 morphants (arrows). The dotted lines in (O, P) outline a single tectal lobe in each embryo. Embryos in (A-N) are shown in lateral view with anterior left, while embryos in $(\mathrm{O}, \mathrm{P})$ are shown in dorsal view with anterior left.

these results suggest that Meis1 positively contributes to ephrin gene expression in the presumptive tectum.

By $48 \mathrm{hpf}$, the tectum has adopted a more mature morphology and the RGC axons have started to innervate their target zones [60]. Therefore, we examined ephrin gene expression in meis 1 morphants again at this developmental stage. Consistent with the results obtained at $32 \mathrm{hpf}$, the expression levels of efna2 $(n=$ $23 / 25)$, efna $3 b(n=16 / 19)$, efna5a $(n=26 / 30)$, and efnb3b $(n=13 / 13)$ are reduced in Meis1-depleted embryos (Figure 2I-P). Taken together, these results suggest that Meis1 is required for proper tectal patterning, a role that may contribute to the retinotopic organization of the zebrafish visual system.

Meis1 knockdown affects early retinal DV patterning and results in a partial ventralization of the retina

The role of Meis1 in patterning the retina has not been previously examined. To determine if Meis1 is involved in specifying DV identity in the retina, we compared the expression of the DV markers $t b x 5$ and $v a x 2$ between wild-type and Meis1-depleted embryos. At $15 \mathrm{hpf}, t b \times 5$ is expressed in the presumptive dorsal retina (Figure 3A). Knockdown of Meis1 reduces both the domain and intensity of $t b \times 5$ expression ( $n=27 / 30$; Figure $3 B$ ). To examine the domain of ventral identity at $15 \mathrm{hpf}$, we looked at the expression of vax2. Compared to wild-type embryos, the retinal domain of vax2 expression is expanded upon Meis1 knockdown ( $n=14 / 19$; Figure 3I, J). Taken together, these data suggest that a loss of Meis1 function results in a reduction in presumptive dorsal retinal identity together with an expansion of ventral identity.

To determine if these early defects in DV patterning persist into later eye development, we examined dorsal $t b \times 5$ and $e f n b 2 a$ and ventral $v a x 2$ and ephb2 expression in 28 -hpf retinas. By this stage, the wild-type zebrafish eye has adopted a more definitive morphology where the neural retina wraps around the lens and meets at the ventral choroid fissure to form a $360^{\circ}$ circle. To quantify changes in retinal axial patterning, we analyzed in situ staining intensity in flat-mounted retinas from 28-hpf wild-type and meis1 morphants and compared 


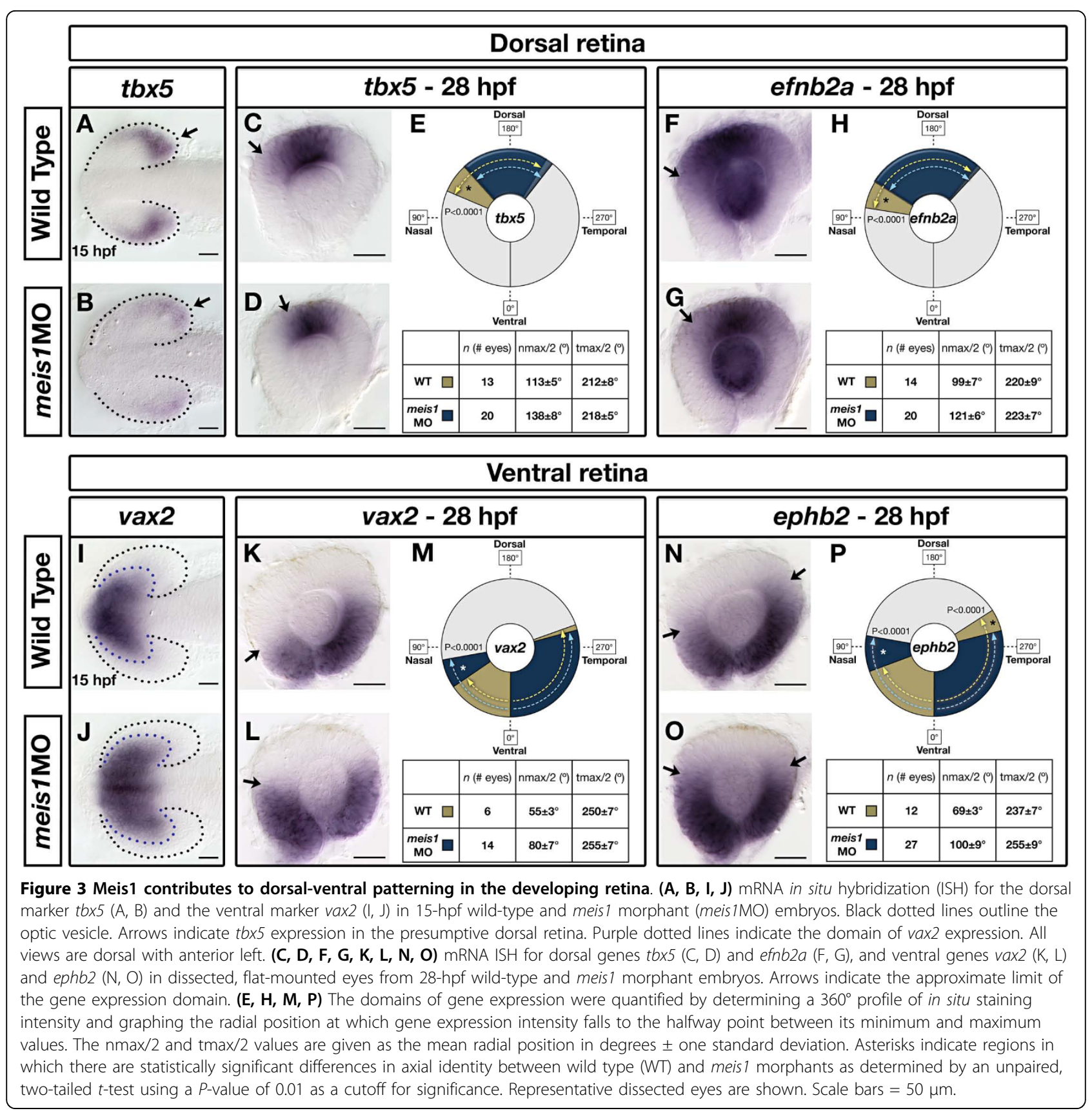

the radial position at which gene expression intensity falls to the halfway point between its minimum and maximum values (see Materials and methods) [27]. Consistent with the defects observed at $15 \mathrm{hpf}$, we find that the extent of $t b x 5$ expression is reduced in 28-hpf meis 1 morphants (Figure $3 \mathrm{C}-\mathrm{E}$ ). This reduction in $t b \times 5$ is primarily at its dorso-nasal boundary, where meis 1 morphants exhibit a $26^{\circ}$ retraction in expression $(P<$ 0.0001 ; Figure $3 \mathrm{E}$ ). In contrast, the dorso-temporal border of $t b x 5$ does not statistically differ between wild type and meis 1 morphants $(P=0.0124$; Figure $3 E)$. efn $b 2 a$ is a transcriptional target of $t b \times 5$ in the dorsal retina. Similar to the changes in $t b x 5$ expression, we find that the dorso-nasal border of efn $b 2 a$ is retracted by $22^{\circ}$ in meis 1 morphants $(P<0.0001)$, and the dorsotemporal border is unchanged $(P=0.3301$; Figure $3 \mathrm{~F}$ $\mathrm{H})$. With regard to ventral identity at $28 \mathrm{hpf}$, we find that the ventro-nasal borders of both vax2 and ephb2 are expanded dorsally by $25^{\circ}$ and $31^{\circ}$, respectively, in meis 1 morphants $(P<0.0001$; Figure $3 \mathrm{~K}-\mathrm{P})$. While the ventro-temporal border of vax2 is not statistically different between wild type and morphants $(P=0.2046)$, the 
ventro-temporal border of ephb2 is retracted ventrally by $18^{\circ}$ in meis 1 morphants $(P<0.0001$; Figure $3 \mathrm{P})$. Overall, these results demonstrate that Meis1 plays a role in specifying DV identity, and that Meis1 knockdown leads to a partial ventralization of the retina, particularly in the ventro-nasal domain.

\section{Meis1 promotes retinal Bmp signalling by regulating smad 1 and follistatin $a$ expression}

The Bmp signalling pathway plays an evolutionarily conserved role in specifying dorsal identity in the retina [5-8]. The DV patterning defects in meis 1 morphants could be due to misregulation of a vital component of the Bmp pathway. Smad transcription factors play an essential role in this process by mediating the transcriptional response to Bmp signalling. We hypothesized that Meis1 might regulate retinal smad1 expression since its domain in the early zebrafish optic vesicle is similar to that of Meis1 protein, and meis1 mRNA expression precedes that of smad1 (Additional file 3A-D). To test this hypothesis, we compared smad1 expression between wild type and meis 1 morphants at $15 \mathrm{hpf}$ and found that smad1 expression is strongly downregulated in the retina of Meis1-depleted embryos $(n=65 / 65$; Figure 4A, B). This phenotype can be rescued by the co-injection of morpholino-insensitive myc-meis1 mRNA ( $n=14 / 15$; Additional file 4A-D), demonstrating the specificity of the meis1 morpholino phenotype. Furthermore, gdf6a morphants have normal levels of smad 1 transcript in the immature eye at $13 \mathrm{hpf}$ (Additional file 5A, B), demonstrating that early smad 1 transcription is not regulated by Bmp signalling. Taken together, these data suggest that Meis1 is a specific regulator of smad1 transcription.

The phosphorylation of Smads 1, 5, and 8 by type I Bmp receptors is an essential step in transducing the Bmp signal into a transcriptional response. To see if the downregulation of smad1 expression had an effect on the total amount of phosphorylated Smads in the retina, we performed whole mount immunohistochemistry using a phospho-Smad1/5/8-specific antibody. At 12 hpf, phospho-Smad staining is reduced in Meis1depleted embryos ( $n=17 / 21$; Figure $4 C$, D). Taken together with the downregulation of $t b x 5$ in Meis1depleted embryos (Figure 3A, B), these data suggest that Meis1 has a positive effect on the level of Bmp signalling during early retinal patterning.

Although the expression of smad1 remains downregulated in meis 1 morphants, the reduced level of phosphoSmad1/5/8 at $12 \mathrm{hpf}$ largely recovers by $15 \mathrm{hpf}$ (compare Figures $4 \mathrm{E}$ and $4 \mathrm{~F}$ ). The presence of other Smad proteins could account for this discrepancy. smad5 is ubiquitously expressed during early development, can act redundantly with smad1 [61-63], and is not transcriptionally regulated by Meis1 (Additional file 6). To determine if the presence of Smad5 is masking the loss of smad1 expression in Meis1-depleted embryos at $15 \mathrm{hpf}$, we performed an interaction experiment using meis1 and smad5 morpholinos. Using the level of phospho-Smads1/5/8 and tbx 5 transcription as an assay for Smad5 function, we observe a decrease in the level of retinal Bmp signalling in smad5 morphants. Knocking down Smad5 protein subtly decreases the level of phospho-Smads1/5/8 ( $n=4 / 4$; compare Figures $4 \mathrm{E}$ and $4 \mathrm{G})$, and reduces $t b x 5$ to levels comparable to that of Meis1depleted embryos $(n=34 / 34$; compare Figures $4 \mathrm{~K}$ with 4I and 4J). However, by combining the two morpholinos, there is a synergistic effect where the level of phospho-Smads $1 / 5 / 8$ is nearly eliminated ( $n=6 / 6$; Figure $4 \mathrm{H})$ and $t b \times 5$ transcript is often undetectable by in situ hybridization ( $n=28 / 39$; Figure $4 \mathrm{~L})$. These results are consistent with the hypothesis that Meis1-regulated transcription of smad1 is important for retinal DV patterning, and that Smad1 and Smad5 perform at least partially redundant functions in the eye.

In addition to positive regulators of retinal Bmp signalling, we also examined the role of Meis1 in regulating the expression of Bmp inhibitors. In particular, we observe that Meis1 knockdown results in an upregulation of $f$ sta expression throughout much of the brain and anterior spinal cord ( $n=48 / 48$; Figure 5A-D; Additional file $1 \mathrm{G}, \mathrm{H})$. Especially striking is the ectopic $f$ sta expression in the retina at $13 \mathrm{hpf}$ (Figure 5B). As with smad1, injection of myc-meis 1 mRNA can partially rescue the $f s t a$ expression defects in meis 1 morphants ( $n=7 / 10$; Additional file 4E-H). Additionally, this phenotype cannot be attributed to a downregulation of Bmp signalling, as $g d f 6 a$ morphants do not exhibit increased $f$ sta expression at $13 \mathrm{hpf}$ (Additional file 5C, D). These data suggest that, in addition to positively regulating smad1 transcription, Meis1 is also a negative regulator of $f$ sta expression.

Fsta is a secreted protein known to bind directly to several different Bmp ligands to prevent Bmp receptor activation [64-66]. Although Fsta can downregulate Gdf6 transcription in Xenopus animal caps [67], a functional antagonism between Fsta and Gdf6 proteins has not been demonstrated. To determine if the upregulation of $f$ sta expression in meis 1 morphants can inhibit $g d f 6 a$ function in the retina, we tested the ability of ectopic $f s t a$ to inhibit the embryonic ventralization phenotype caused by the injection of human GDF6 mRNA into one-cell embryos (Figure 5E). As little as $10 \mathrm{pg}$ of GDF6 mRNA is sufficient to cause a ventralized phenotype in $92 \%$ of the embryos, with $50 \%$ of embryos lacking all anterior head structures $(n=38$; Figure $5 \mathrm{E}$, bar $3)$. Conversely, $200 \mathrm{pg}$ of $f$ sta mRNA alone causes a dorsalized phenotype in $38 \%(n=37)$ of the injected 


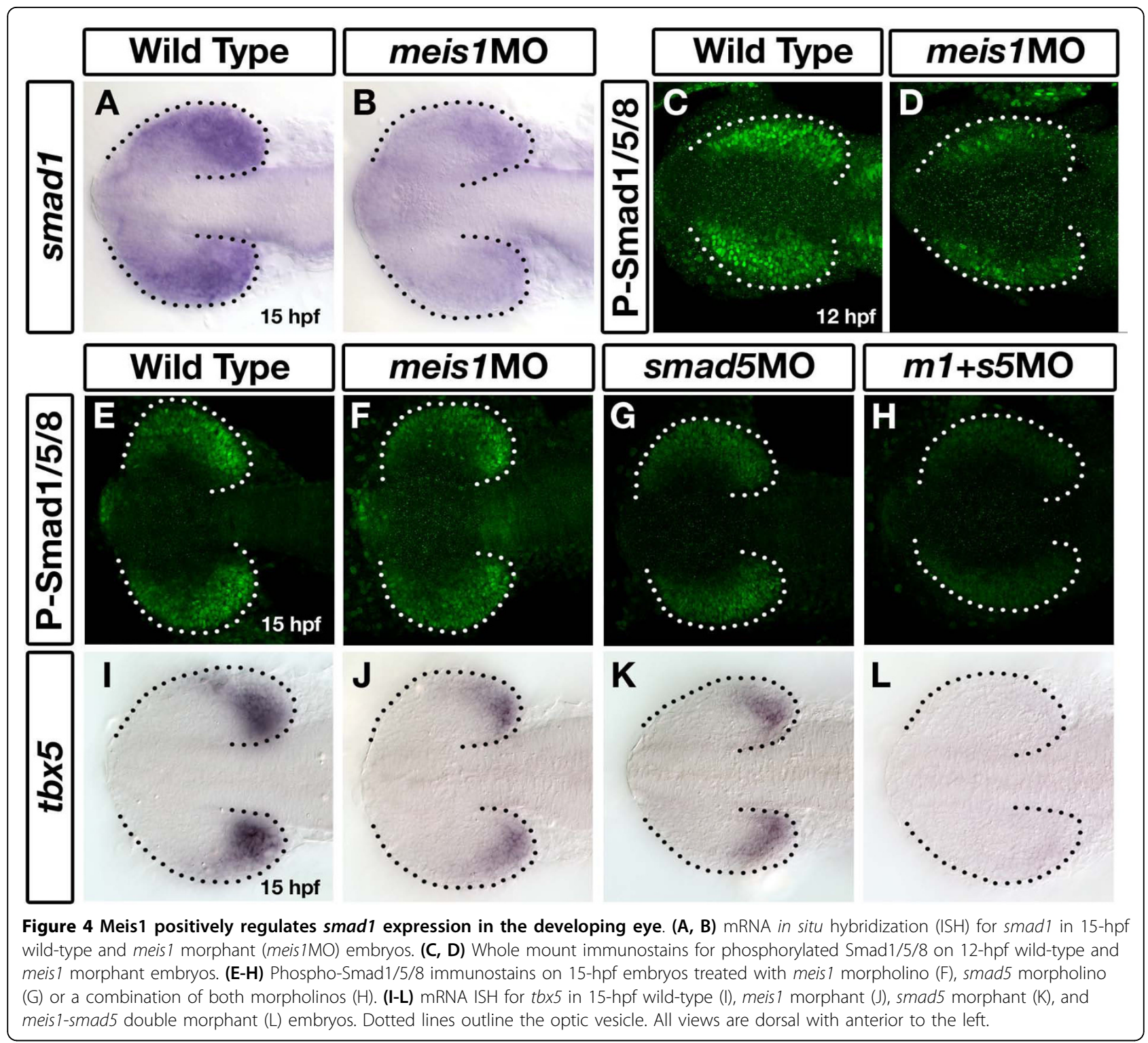

embryos (Figure 5E, bar 2). Injecting $200 \mathrm{pg}$ of $f$ sta mRNA together with $10 \mathrm{pg}$ of GDF6 mRNA effectively inhibits the ventralizing effects of GDF6 (Figure 5E, bar 4). Following this treatment, no severely ventralized embryos were observed, and only $14 \%$ had a mildly ventralized phenotype $(n=32)$. To test if $f$ sta can inhibit endogenous Gdf6a signalling in the zebrafish retina, we injected $100 \mathrm{pg}$ of fsta mRNA into a single cell of twocell embryos and examined the level of phosphoSmads1/5/8 at $14 \mathrm{hpf}$ by whole-mount immunohistochemistry. This asymmetrical injection of $f$ sta mRNA causes uniocular reductions of phospho-Smads $1 / 5 / 8$ $(n=5 / 8$; Figure $5 F, G)$. Together, these results suggest that Fsta can inhibit Gdf6a-mediated signalling, and that the upregulation of $f s t a$ expression in meis 1 morphants may contribute to the retinal DV patterning defects observed in these embryos.

In summary, Meis1 knockdown causes a dorsal-toventral shift in retinal identity that correlates with a reduced level of Bmp signalling in the optic vesicle. This decreased Bmp signal in meis1 morphants can be attributed to a loss of smad1 expression and an upregulation of $f$ sta. Thus, Meis1 plays an important role in retinal DV patterning by facilitating ocular Bmp signalling.

\section{Meis1-knockdown causes a partial loss of temporal} identity in the retina

During early zebrafish eye development, the nasal and temporal axes are initially established in the dorsal and ventral leaflets of the optic vesicle, respectively [28]. As 

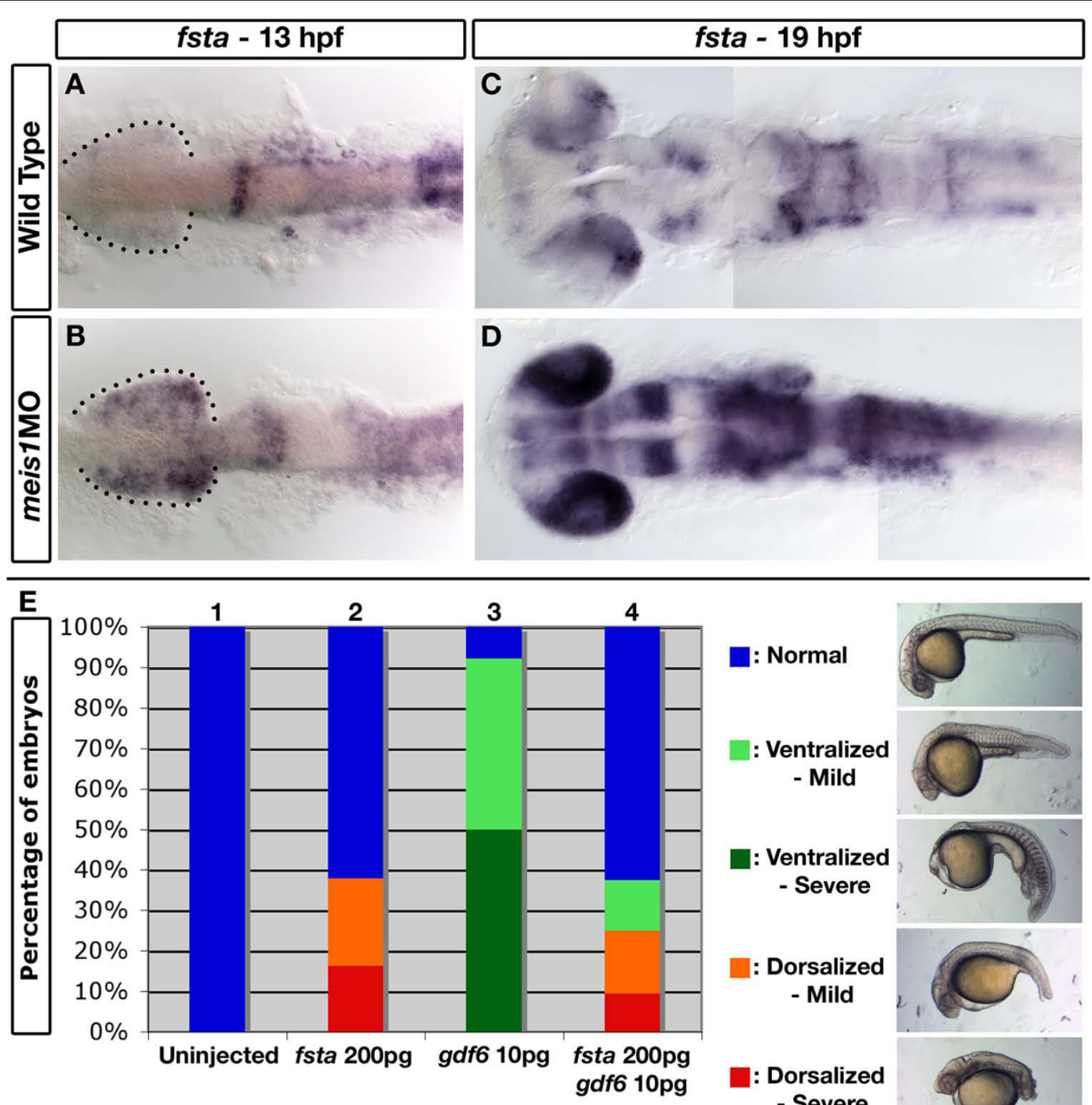

Type of mRNA injection
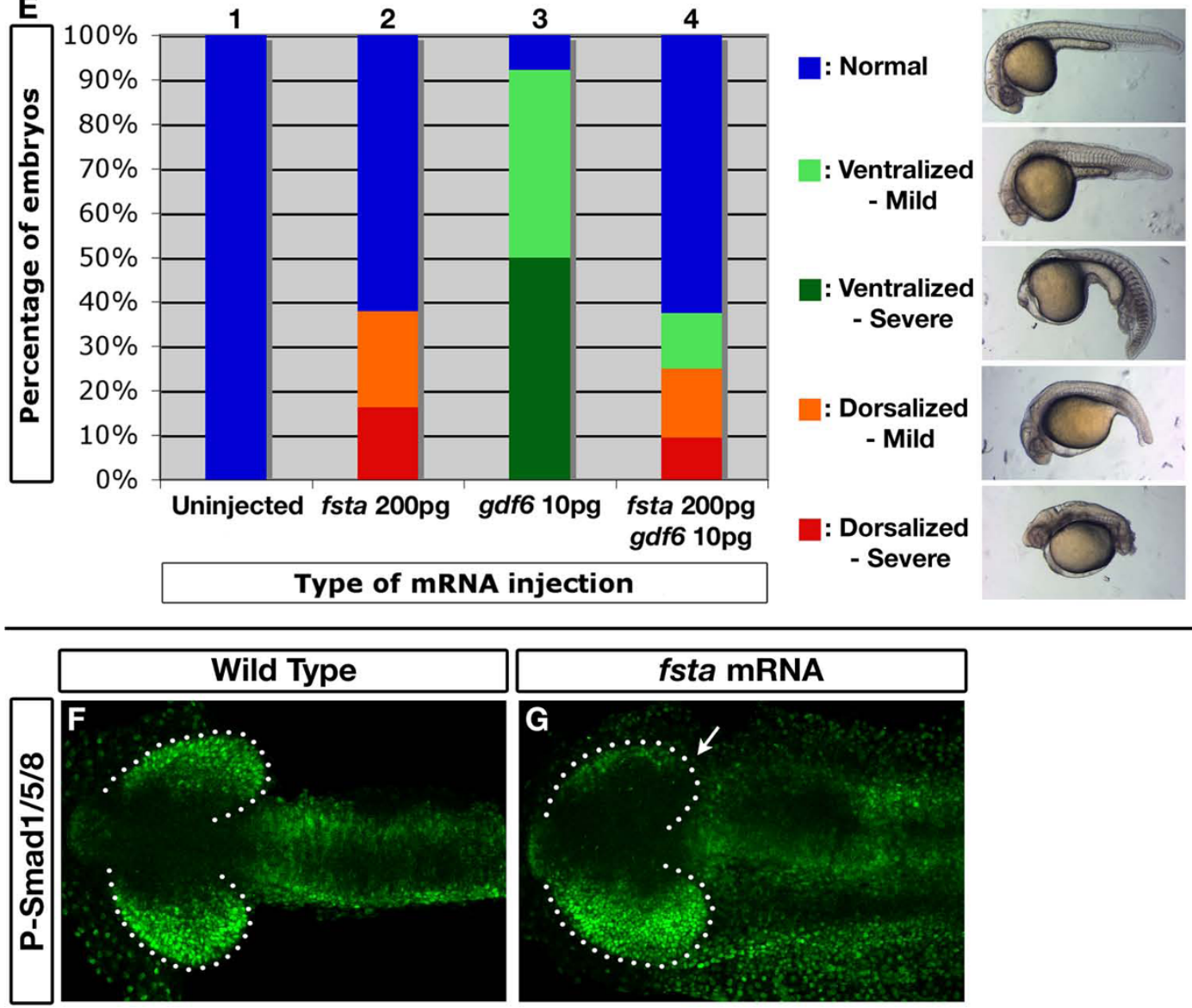

Figure 5 follistatin $a$ is ectopically expressed in Meis1-depleted embryos and can inhibit Gdf6-mediated Bmp signalling. (A-D) mRNA in situ hybridizations for fsta on 13-hpf (A, B) and 19-hpf (C, D) wild-type and meis1 morphant (meis 1MO) embryos. Dotted lines outline the optic vesicle. All views are dorsal with anterior to the left. (E) Results of the GDF6-Fsta interaction experiments. One-cell embryos were injected with either 200 pg of zebrafish fsta mRNA (bar 2), human GDF6 mRNA (bar 3), or both mRNAs (bar 4), raised until 28 hpf, and scored for dorsalized and ventralized phenotypes (see legend on the right for classification). (F, G) Confocal images of whole mount immunostains for phospho-Smad1/5/8 in wild-type and fsta mRNA-injected embryos at 14 hpf. Injection of fsta mRNA into one cell of a two-cell embryo causes a unilateral reduction in phospho-Smad1/5/8 staining (arrow in G). Dotted lines outline the optic vesicle. Views are dorsal with anterior to the left. 
the retina develops, foxd1-expressing cells in the ventral leaflet move into the dorsal leaflet to form the temporal domain of the neural retina. To determine if Meis1 regulates positional identity along the NT axis, we examined foxgla and foxd1 mRNA expression in the presumptive nasal and temporal domains. In 15-hpf wild-type embryos, foxgla is expressed in the dorsal leaf of the optic vesicle, specifically the proximal region fated to form the nasal retina (Figure 6A). In meis 1 morphants, this domain of foxgla expression is expanded distally, suggesting an expansion of nasal identity ( $n=31 / 54$; Figure 6B). Likewise, in 15 -hpf wildtype embryos, foxd 1 is also expressed in the dorsal optic vesicle, but in a domain underlying, and more distal to, that of foxg1a (Figure 6F). In 15 hpf meis1 morphants, cells in the dorsal optic vesicle do not express foxd1 $(n=44 / 52$; Figure 6G; Additional file 1E, F). Instead, faint foxd1 expression is observed in the ventral leaflet, suggesting that foxd1-expressing cells have failed to move into the dorsal leaflet of the optic vesicle. We also examined the temporally restricted expression of epha7 at $16 \mathrm{hpf}$ and found that its expression is similarly reduced in Meis1-depleted embryos (Additional file 7A, B). Together, these results suggest that Meis 1 is an important regulator of early NT patterning.

To see how these early defects in NT patterning translate into later phenotypes, we quantified the expression domains of foxg1a and foxd1 in dissected 28-hpf retinas. At this later stage, there is no significant expansion of nasal foxg1a expression towards the dorsal pole in Meis1-depleted retinas $(P=0.5457$; Figure 6C-E). Conversely, the dorso-temporal border of foxd 1 expression is retracted ventrally by $25^{\circ}$ in Meis 1 -depleted retinas $(P<0.0001$; Figure $6 \mathrm{H}-\mathrm{J})$. Consistent with this latter observation, we also find that the expression domains of epha7 $(n=14 / 14)$ and epha4b $(n=18 / 20)$ in the temporal retina are also reduced in meis 1 morphants (Additional file 7C-F). Together, these data support the idea that Meis1 plays a role in NT patterning, especially with regard to the establishment of foxd 1 and ephA expression in the temporal retina.

\section{The contribution of Fgf signalling to the NT patterning defects in Meis1-depleted embryos}

The Fgf signalling pathway establishes nasal identity in the developing retina [26-28]. Ectopic Fgfs expand nasal identity at the expense of temporal fate, while inhibition of the pathway has the opposite effect. Since some aspects of the meis1 morphant phenotype resemble that of ectopic Fgf signalling, we examined the effect of Meis1-depletion on $i l 17 \mathrm{rd} / \mathrm{sef}$ and $d u s p 6$ expression, two genes whose transcription is positively controlled by the Fgf pathway [68-71]. As seen in the dorsal view, both il17rd (Figure 7A) and dusp6 (Figure 7C) are expressed in the dorsal forebrain, optic stalk and faintly in the presumptive nasal retina of 15-hpf wild-type embryos. Meis1 knockdown results in broader domains of il17rd $(n=27 / 48$; Figure 7B) and dusp6 $(n=18 / 30$; Figure 7D) expression in the dorsal forebrain and presumptive nasal retina. Transverse cross-sections also reveal that the nasal expression domains of il17rd and dusp 6 are expanded laterally in 15-hpf Meis1-depleted embryos (il17rd in Figure 7E, E', F, F'; dusp6 in Figure 7G, G', H, $\left.\mathrm{H}^{\prime}\right)$. Thus, we can conclude from these experiments that there is a subtly higher level of Fgf signalling in the eyes and forebrain of meis 1 morphant embryos.

To determine whether the expanded range of Fgf signalling contributes to the NT patterning defects in meis1 morphants, we antagonized Fgf signalling using a pharmaceutical inhibitor of Fgf receptors (PD173074). Changes in NT patterning were assayed by in situ hybridization for the nasal marker efna $5 a$ and the temporal marker epha3 and quantified by radial profiling of in situ intensity. Consistent with the NT patterning defects shown in Figure 6 and Additional file 7, meis 1 morphants exhibit an expansion of nasal efna $5 a$ (mean shift of $14^{\circ} ; P<0.0001$; Figure $8 \mathrm{~A}, \mathrm{C}, \mathrm{E}$ ) and a reduction in temporal epha3 expression compared to wild type $\left(20^{\circ}\right.$; $P<0.0001$; Figure 8F, H, J). Fgf receptor (FgfR) inhibitor-treated embryos exhibit a partial loss of nasal identity $\left(56^{\circ} ; P<0.0001\right.$; Figure $\left.8 \mathrm{~B}, \mathrm{E}\right)$, and an expansion of the temporal domain $\left(49^{\circ} ; P<0.0001\right.$; Figure $\left.8 \mathrm{G}, \mathrm{J}\right)$. Compared to the meis 1 morphant phenotype alone, morphants treated with the FgfR inhibitor exhibit reduced efna 5 a expression ( $46^{\circ}$ difference; $P<0.0001$; Figure 8D, E), and have an expanded domain of epha3 expression (19 ${ }^{\circ}$ difference; $P<0.0001$; Figure 8I, J). However, neither of these phenotypes are as profound as those caused by the FgfR inhibitor treatment alone. This is true with regard to both efna $5 a$ and epha3 expression, where inhibition of Fgf signalling in meis 1 morphants does not cause the same robust shifts in axial identity as it does in uninjected embryos. Similar results were observed in experiments using the Fgf receptor inhibitor SU5402 (data not shown). Together, these data suggest that the subtle expansion of Fgf signalling in Meis1-depleted embryos is unlikely to be the sole reason for the observed shifts in NT identity.

\section{Meis1 knockdown results in retinotectal map defects}

Having established that Meis1 plays an early developmental role in patterning the retina and tectum, we next determined whether this early function had a later effect on tectal development and the formation of the retinotectal map. To compare the size of the tectal neuropil, we stained 5-dpf wild-type and meis 1 morphant embryos using an antibody against acetylated tubulin to mark axons and with Hoechst 33258 to mark nuclei 

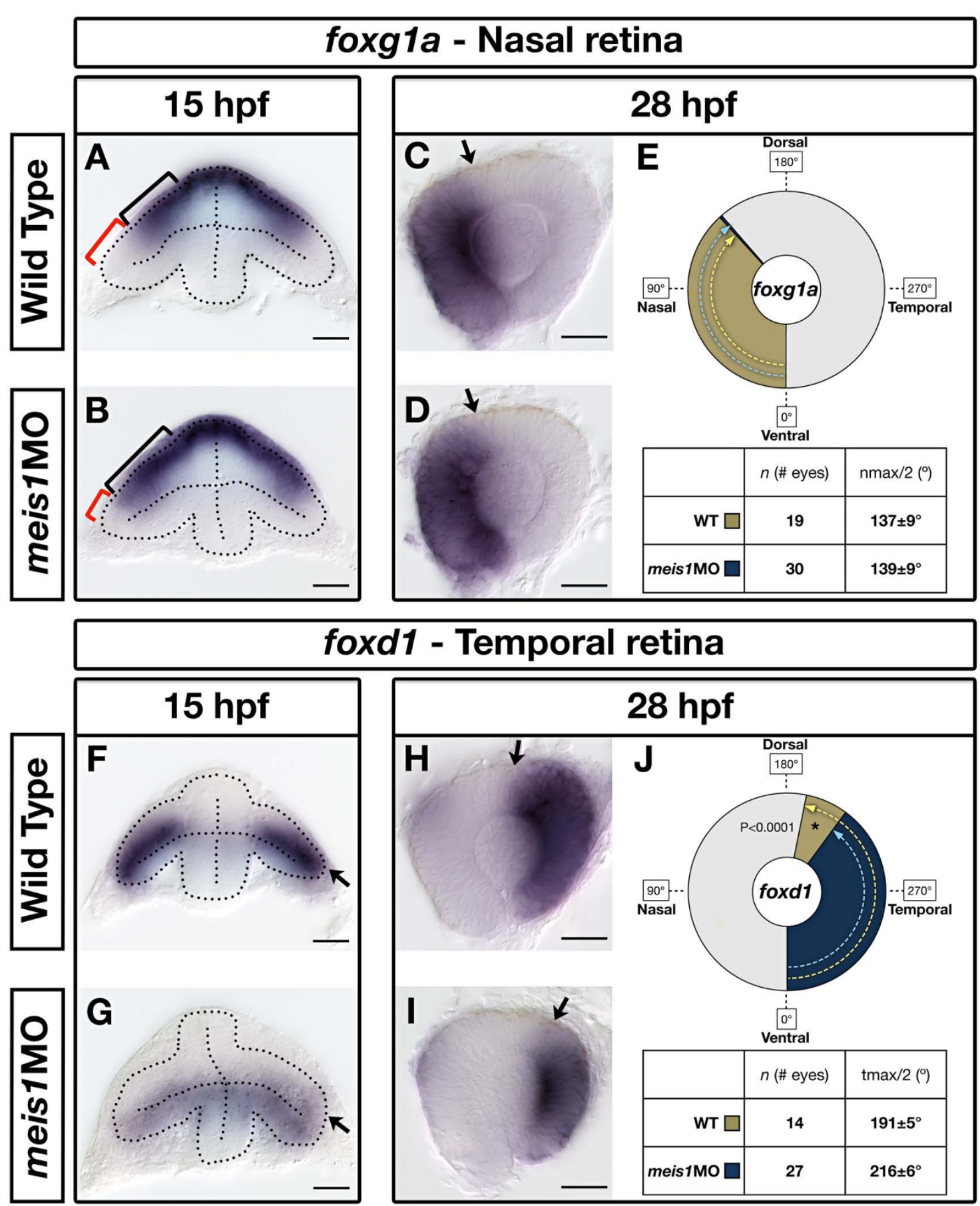

Figure 6 Meis1-depleted embryos exhibit a partial temporal-to-nasal shift in retinal identity. (A, B, F, G) mRNA in situ hybridization (ISH) for the nasal marker foxgla (A, B) and the temporal marker foxd1 (F, G) in 15-hpf wild-type and meis 1 morphant (meis1MO) embryos. Dotted lines outline the optic vesicle. The black brackets in (A, B) indicate the proximal-distal extent of foxg 1 a expression, while the red brackets indicate the foxgla-free region. Arrows in $(F, G)$ indicate the dorsal leaflet of the optic vesicle. Transverse sections are oriented dorsal up. (C, D, $\mathbf{H}, \mathbf{I})$ mRNA ISH for the nasal marker foxg1a (C, D) and the temporal marker foxd1 $(H, I)$ in dissected, flat-mounted eyes from 28-hpf wild-type and meis 1 morphant embryos. The arrows indicate the approximate limit of the gene expression domain. $(\mathbf{E}, \mathbf{J})$ The domains of gene expression were quantified by determining a $360^{\circ}$ profile of in situ staining intensity and graphing the radial position at which gene expression intensity falls to the halfway point between its minimum and maximum values. The nmax/2 and tmax/2 values are given as the mean radial position in degrees \pm one standard deviation. Asterisks indicate regions in which there are statistically significant differences in axial identity between wild type and meis 1 morphants as determined by an unpaired, two-tailed $t$-test using a $P$-value of 0.01 as a cutoff for significance. Representative dissected eyes are shown. Scale bars $=50 \mu \mathrm{m}$. 


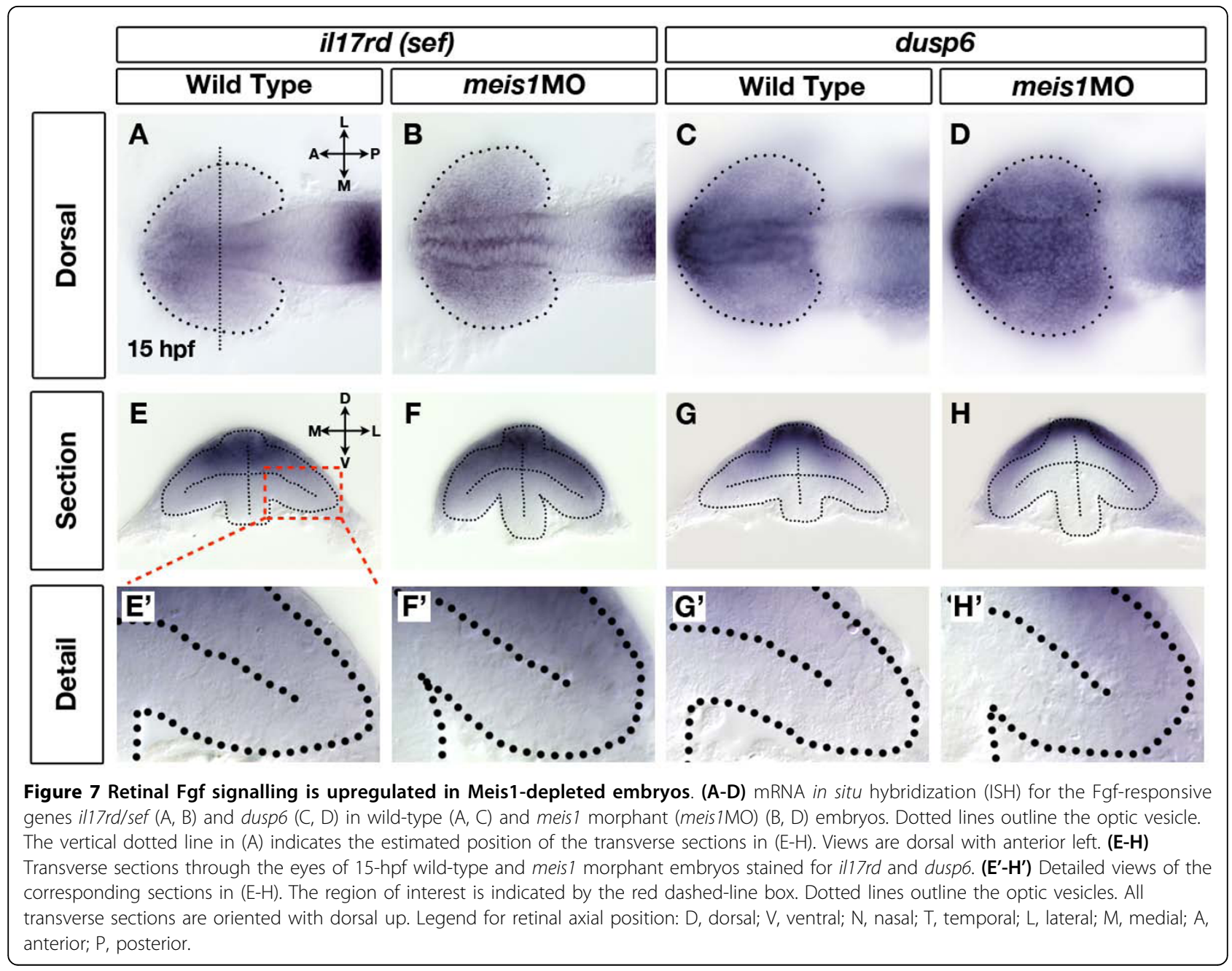

(Figure 9A-F). Morphant neuropil ( $n=34$ individual neuropil) are $50 \%$ smaller on average than their wildtype counterparts $(n=13$ individual neuropil; $P<$ 0.0001; Figure 9B'). However, acetylated tubulin-positive axons are still present in morphant tecta $(n=19 / 19$; Figure 9E-F), suggesting that although the tectum is smaller, its morphology is grossly normal in Meis1depleted embryos.

To find out if Meis1-depleted embryos have retinotectal mapping defects, we injected DiI and DiO fluorescent lipophilic dyes into specific axial regions of 5-dpf retinas and visualized the mapping patterns of the RGC axons by confocal microscopy. With regard to the retinal DV axis, wild-type dorsal RGCs (red) innervate the lateral tectum, while ventral RGCs (green) project to the medial region (Figure 10A-C). Along the NT axis, wildtype nasal RGCs (red) innervate the posterior tectum, while temporal RGCs (green) project to the anterior region (Figure 10G-I). Meis1-depleted embryos exhibit defects in DV mapping, where the innervation zones of the dorsal and ventral RGC axons partially overlap in the tectum ( $n=18 / 47$; Figure 10D-F). Although, the normal medial-lateral restriction is lost in morphants for both dorsal and ventral axons, the ventral axons tend to exhibit a broader innervation pattern than dorsal axons (compare Figures 10B and 10E). We observe similar results with regard to the NT retinotectal map in meis 1 morphants, in which the innervation zones of the nasal and temporal RGC axons overlap in the tectum $(n=25$ / 64; Figure 10J-L). Again, while normal anterior-posterior segregation of axons is lost for both the nasal and temporal axons, temporal axons tend to be more broadly distributed in the tectum (compare Figures $10 \mathrm{H}$ and $10 \mathrm{~K})$. Although overlapping innervation patterns are a common phenotypic class in meis1 morphants, we also frequently observe a partial or complete axon stalling phenotype (DV, $n=15 / 47$; NT, $n=23 / 64$; Figure 10M; Additional file 8). These data demonstrate that Meis1 function is required to correctly organize the retinotectal map. 

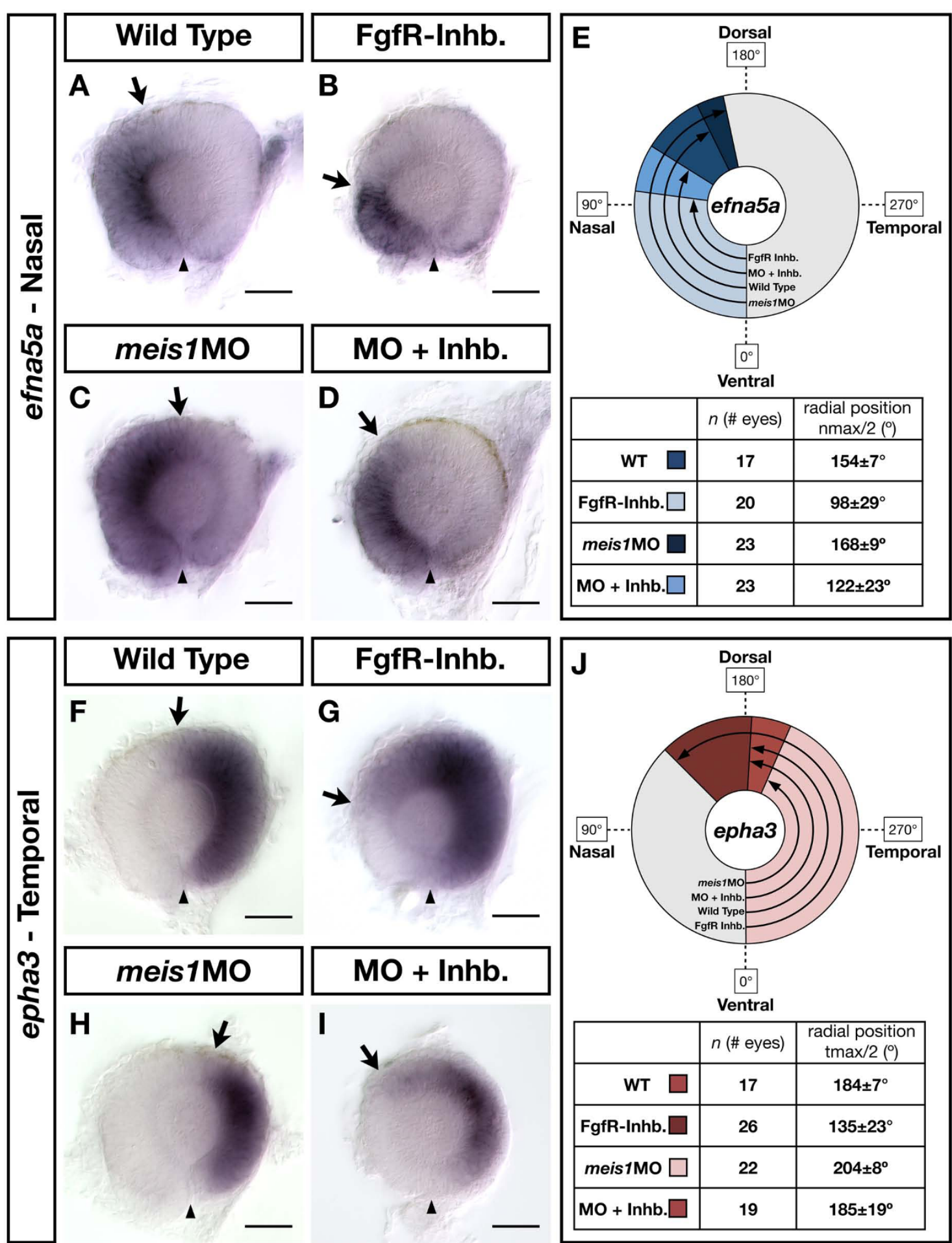

Figure 8 The contribution of Fgf signalling to the NT patterning defects in Meis1-depleted embryos. (A-D, F-I) mRNA in situ hybridizations for the NT markers efna5a (A-D) and epha3 (F-I) in wild type, Meis1-depleted (meis 1MO), Fgf receptor-inhibitor treated (FgfR-Inhb.), and FgfR-inhibited/Meis1-depleted retinas ( $\mathrm{MO}+\operatorname{Inhb}$.). Arrows indicate the extent of the gene expression domain, while the arrowheads indicate the position of the ventral choroid fissure. Representative dissected eyes are shown oriented with dorsal up and nasal to the left. Scale bars $=50 \mu \mathrm{m} . \mathbf{( E ,} \mathbf{J})$ Quantification of the changes in efna5a and epha3 expression, as quantified by measuring a $360^{\circ}$ profile of in situ staining intensity and graphing the mean radial position at which gene expression intensity falls to the halfway point between its minimum and maximum values. The nmax/2 and tmax/2 values are given as the mean radial position in degrees \pm one standard deviation. WT, wild type. 


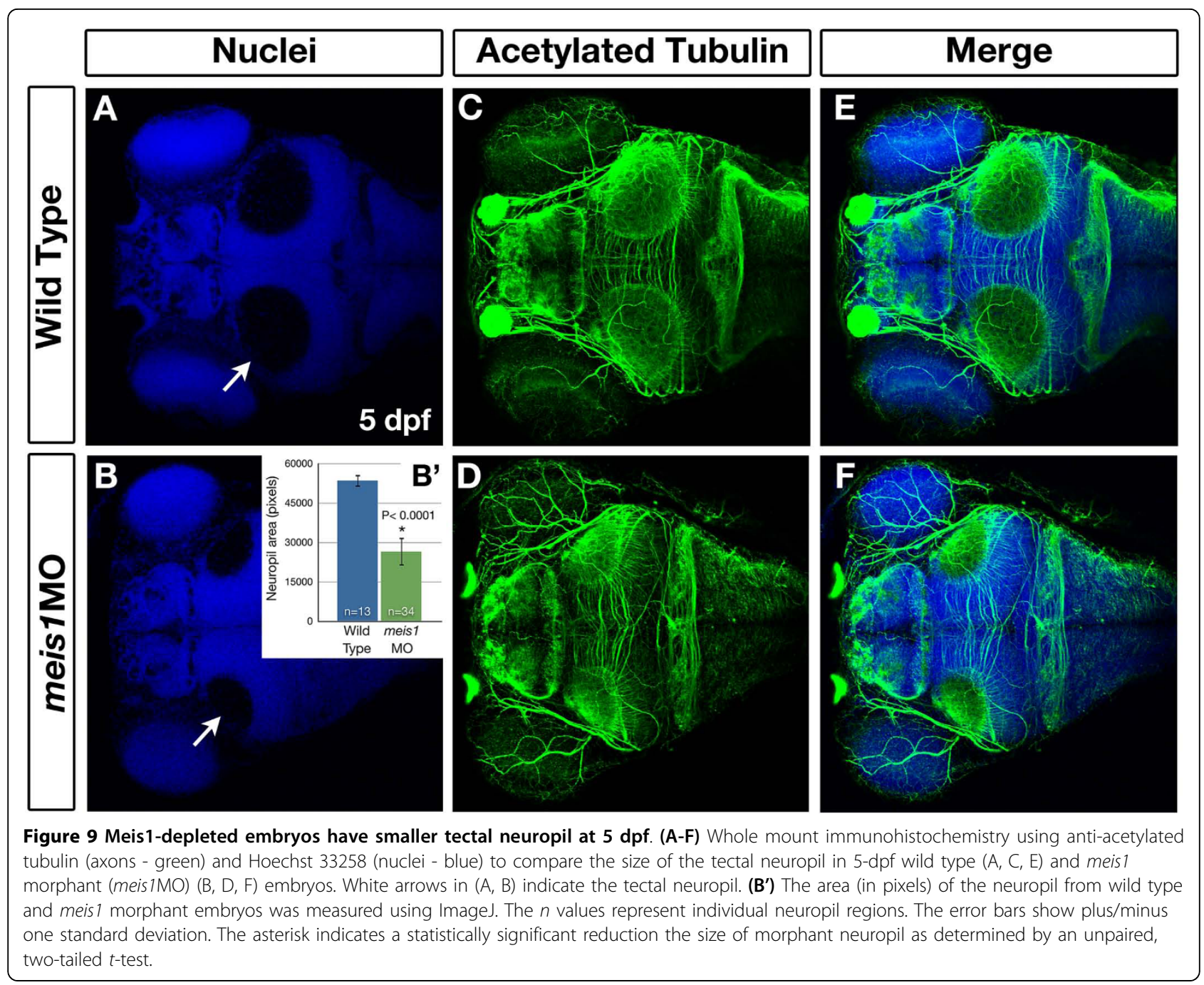

\section{Discussion}

Meis 1 is required to establish tissue polarity throughout the anterior neural tube

meis 1 is expressed in the eye field, the midbrain and hindbrain during the crucial period in which axial identities are established in these tissues. Consistent with the known role for Meis proteins in patterning the hindbrain (TE, unpublished observations) [37,38,72], in this work we demonstrate a specific role for Meis1 in establishing axial polarity in the presumptive tectum and retina. The tectum exhibits a strong anterior-posterior polarity that is reflected in opposing gradients of eph and ephrin expression [29]. In this paper, we show that Meis1 establishes polarity in the zebrafish tectum by positively regulating efna 2 , efna $3 b$, efna $5 a$, and efnb3 expression. This is consistent with what has been found in other model organisms where murine Meis2 patterns the superior colliculus by directly activating ephA 8 expression [56] and chick Meis2 promotes tectal ephrin
B1 expression, possibly via a direct interaction with Otx2 [59]. The functions of Meis1 in regulating eph and ephrin expression are independent of any role in midbrain-hindbrain boundary formation (Additional file 2), again consistent with Meis2 function in chick [59]. Lastly, while meis 1 is also expressed in the developing eye, its role in patterning this tissue has not been explored. In this paper, we show that Meis1 influences the specification of the DV and NT axes in the retina. Taken together, these studies demonstrate that Meis1 contributes to the establishment of axial polarity in anterior neural tissues such as the hindbrain, midbrain and retina.

The axial patterning roles of Meis 1 contribute to formation of the retinotectal map

Meis1-depleted embryos exhibit a range of aberrant retinotectal pathfinding phenotypes, the most common of which are topographic mapping defects in the tectum 

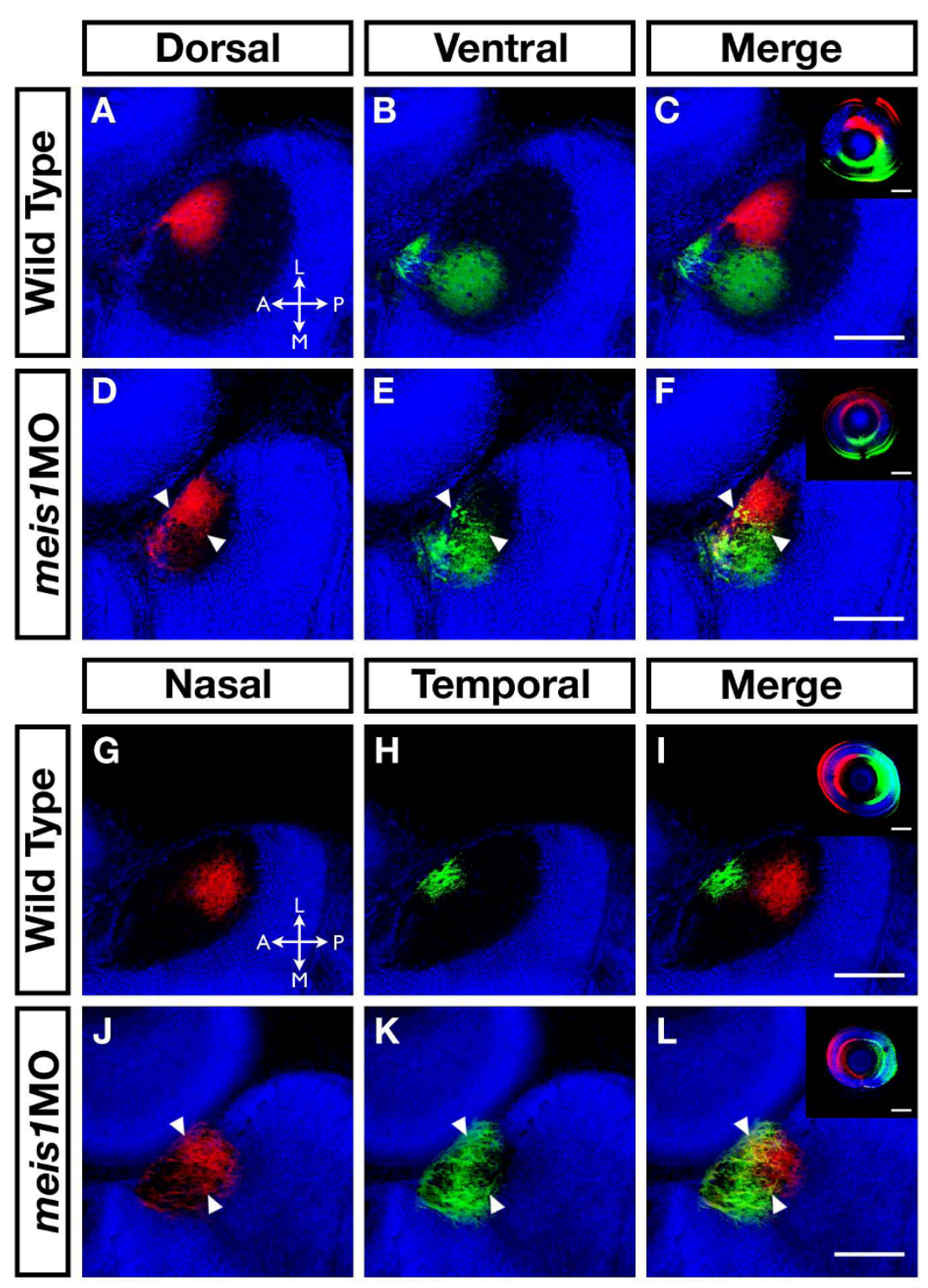

\begin{tabular}{|l|c|c|}
\hline $\mathbf{M}$ meis1MO phenotype & Dorsal-Ventral & Nasal-Temporal \\
\hline Patterning Defect (overlap) & 18 & 25 \\
\hline Axons overshoot the tectum & 1 & 3 \\
\hline No tectal innervation (stalling) & 15 & 23 \\
\hline Wild type-like & 13 & 13 \\
\hline Total $(n)$ & 47 & 64 \\
\hline
\end{tabular}

Figure 10 The retinotectal map is disorganized in Meis1-depleted embryos. (A-L) Lipophilic fluorescent dyes Dil (red) and DiO (green) were injected into specific axial positions of the retina of fixed 5-dpf wild-type and meis 1 morphant embryos and innervation patterns of the ganglion cell axons on the tectum were imaged by confocal microscopy. Nuclei are stained with Hoechst 33258 (blue). The wild-type (A-C) medial-lateral segregation of dorsal (red) and ventral (green) ganglion cell axons in the tectum is lost in meis 1 morphants (white arrowheads in (D-F)). Similarly, the wild-type (G-I) anterior-posterior segregation of nasal (red) and temporal (green) ganglion cell axons in the tectum is disorganized in meis 1 morphants (white arrowheads in (J-L)). The insets in (C, F, I, L) are lateral views of injected retinas from the embryos shown in the corresponding panels. Retinas are oriented with dorsal up and nasal to the left, while all tectal views are dorsal with anterior to the left. Legend for axial position in the tectum: L, lateral; M, medial; A, anterior; P, posterior. All scale bars $=75 \mu \mathrm{m}$. (M) Table describing the frequency of various retinotectal mapping phenotypes observed in meis1 morphants (meis1MO). No retinotectal mapping defects were observed in any wild-type embryos examined. 
(Figure 10) and axon stalling (Additional file 8). While it is clear that Meis1 plays a role in the early patterning of the presumptive DV and NT axes, these patterning phenotypes are not as robust by the time the retinal axes have assumed their final anatomical positions (Figures 3 and 6). Indeed, by $28 \mathrm{hpf}$, the axial patterning defects in meis 1 morphants are milder than what is seen in embryos with decreased levels of Gdf6a or increased Fgf function $[5,6,27,28]$. However, the retinotectal mapping defects in meis 1 morphants are more profound than expected on the basis of observed retinal patterning defects. These data suggest that the loss of Meis1 causes pleiotropic effects throughout the zebrafish visual system. Meis 1 is also a regulator of retinal progenitor cell proliferation $[47,48]$, the relevance of which to eye patterning is not yet understood. Furthermore, we observe defects in tectal size and morphology in meis1 morphant zebrafish (Figure 8) and an expansion of the optic stalk (Additional file 2E, F). Taken together, while it is clear that Meis1 plays a part in specifying positional information in both the retina and tectum, it is possible that this patterning role is but one way that Meis1 contributes to the organization of the retinotectal map.

\section{Meis1 is a positive regulator of retinal Bmp signalling}

The requirement for $\mathrm{Bmp}$ activity in regulating dorsal retinal identity and the retinotectal map has been well established [5-8,73-76]. A decrease in Bmp signalling leads to a loss of dorsal markers such as $t b \times 5$ and an expansion of ventral identity as marked by vax2. We observe similar changes in meis1 morphants, suggesting that Meis1 can potentiate Bmp signalling in the retina (Figure 3). Meis1 regulates the Bmp pathway in at least two ways: first, by positively regulating smad1 transcription (Figure 4); and second, by repressing $f$ sta expression (Figure 5). Meis proteins have not been previously characterized as positive regulators of Bmp signalling, and as such, these results point to a new role for Meis1 in the regulation of neural patterning.

Meis proteins are typically thought to act as transcriptional activators by facilitating histone acetylation at target promoters $[52,77,78]$. For this reason, the ectopic fsta expression observed in meis 1 morphants is likely not due to Meis1 directly repressing $f s t a$, although transcriptional repression by TALE-class proteins is not unheard of [79]. On the other hand, the downregulation of smad1 transcription in meis 1 morphants is consistent with it being directly activated by Meis1. meis 1 and smad1 are co-expressed in the presumptive retina during early development, and we observe that smad1 expression is never initiated properly in meis 1 morphants. Furthermore, we have identified two putative Meis binding sites in a region upstream of the smad1 coding sequence that is conserved between zebrafish
(Danio rerio), Medaka (Oryzias latipes), the green spotted pufferfish (Tetraodon nigroviridis), and the three-spined stickleback (Gasterosteus aculeatus) (TE, unpublished observations). Further analyses will determine whether these sites are functionally significant. Very few studies of smad1 transcriptional regulation have been done [80,81]; thus, the Meis1-dependent activation of $\operatorname{smad} 1$ transcription is an important finding in this area, and represents a novel mechanism of tissuespecificity in Bmp regulation.

Smads1 and 5 have been shown to act redundantly in some processes, such as bone formation and tumour suppression [61-63], yet perform distinct functions during embryonic DV patterning and blood development $[82,83]$. The delayed onset of Smad1/5/8 phosphorylation in meis 1 morphants suggests that Smad1 may be especially important during the initiation of retinal Bmp signalling. However, the results of the meis1-smad5 morpholino interaction experiment suggest that Smad1 and Smad5 have partially redundant functions, at least with regard to activating $t b x 5$ expression. These results suggest that Smad1 and 5 have differential and overlapping roles in patterning the zebrafish retina.

\section{Meis 1 is an important factor in the specification of the temporal retina}

Vertebrate eye patterning is characterized by a complex series of interactions in which cell identity, proliferation and eye morphogenesis $[84,85]$ must be spatially and temporally coordinated. This has been best described with regard to nasal specification in the zebrafish retina by Fgfs 3,8 , and 24 [27,28]. In this case, the movement of temporally fated cells from the ventral leaflet of the optic vesicle is required to compact the future nasal domain, thereby defining the relative sizes of these two axes. Thus, patterning of the NT axis is intimately linked with eye morphogenesis.

Meis1-depleted embryos display defects in NT patterning, especially with regard to the specification of the temporal retina. The early expression of foxd1, an essential regulator of temporal identity, is downregulated in meis 1 morphants (Figure 6F, G). Furthermore, the DV position of foxd1-expressing cells is altered in Meis1depleted embryos compared to equivalently staged wildtype embryos. By $15 \mathrm{hpf}$, foxd1-expressing cells have largely moved from the ventral optic vesicle leaflet to the dorsal leaflet in wild-type embryos. However, in meis 1 morphants, foxd1-expressing cells are still located in the ventral leaflet, suggesting that temporal cell movements into the neural retina are impaired in Meis1-depleted embryos. Foxd1 is known to regulate ephA expression in the temporal retina [20]. Since Ephs and Ephrins are involved in cell sorting and adhesion [86], the decrease in temporal epha3, epha4b, and epha7 
expression (Figure 8; Additional file 7) is likely to alter cohesive cell behaviours amongst temporal retinal progenitors and may contribute to hampered cell movements in meis1 morphants.

We also observe a subtle expansion of Fgf signalling in the optic vesicle of meis1 morphants (Figure 7A-H') that could contribute to the NT patterning defects. Indeed, a partial inhibition of Fgf signalling in meis1 morphants is sufficient to restore temporal identity to at least wildtype levels (Figure 8). However, the nasal-to-temporal shift in axial identity caused by FgfR-inhibitor treatment is not as robust in Meis1-depleted embryos as in uninjected controls. As such, these data suggest that expanded Fgf signalling is unlikely to be the only contributing factor to the NT patterning defects in Meis1depleted embryos. The balance between nasal and temporal identity is mechanistically complex and interdependent [28], and the early expansion of Fgf signalling and foxg1a expression in 15-hpf meis1 morphants could be a consequence, rather than a cause, of decreased temporal identity. Consistent with this idea is the observation that temporal identity is robustly reduced in meis 1 morphants at both $15 \mathrm{hpf}$ and $28 \mathrm{hpf}$ (Figure 6FJ; Additional file 7), whereas the expansion of nasal identity and Fgf signalling is more variable at these same stages (Figures 6A-E and 7). Furthermore, we do not observe any consistent change in the expression of $f g f 3, f g f 8$, or $f g f 24$ between the stages of 12 and $15 \mathrm{hpf}$ (data not shown). It is currently unknown if the temporal retina is actively specified, and future studies will determine whether Meis1 plays a specific role in regulating temporal retinal identity.

\section{Conclusions}

In this work, we demonstrate that the homeodomain transcription factor Meis1 plays an important role in axial patterning of both the retina and tectum, thereby contributing to retinotectal map formation in zebrafish. We describe a novel role for Meis1 in the positive regulation of retinal Bmp signalling by activating smad1 transcription and repressing $f$ sta expression. Additionally, Meis1 plays an important role in specifying temporal identity in the retina. Lastly, Meis1 positively regulates the expression of ephrin genes in the tectum. In summary, Meis1 functions to specify positional information throughout the visual system to support the retinotopic organization of ganglion cell axons on the optic tectum.

\section{Materials and methods}

\section{Fish lines and maintenance}

Adult fish were cared for according to standard protocols [87]. The AB strain of wild-type fish was used for all experiments. Embryos were grown at either $25.5^{\circ} \mathrm{C}$, $28.5^{\circ} \mathrm{C}$, or $33^{\circ} \mathrm{C}$ and staged according to Kimmel et al. [88]. Embryos that were analyzed past the stage of $24 \mathrm{hpf}$ were grown in embryo media supplemented with 0.003\% 1-phenyl 2-thiourea (PTU; Sigma-Aldrich, St. Louis, MO, USA) to prevent pigment formation. We find that the meis1 morpholino causes a small delay in development (approximately 1 hour younger at $24 \mathrm{hpf}$ ). We have used somite counts, tail curvature and eye morphology to equalize stages between uninjected controls and morphants, and have analyzed multiple developmental stages to demonstrate that the morphant phenotypes do not reflect a case of developmental delay.

\section{Morpholinos, mRNA injections, and Fgf receptor inhibition}

All morpholinos were purchased from Gene Tools (Philomath, OR, USA) and dissolved to their working concentrations in Danieau buffer. The meis1 [44], gdf6a [89], and smad5 [83] morpholinos have all been described previously. The second, non-overlapping meis1 morpholino (meis1NOL: CCCTCCACACTCC CTCGTCTTCCTT) was used at a concentration of 2 $\mathrm{mg} / \mathrm{ml}$ and approximately $2 \mathrm{nl}$ was injected into one-cell embryos. fsta, GDF6, and myc-meis 1 mRNAs were synthesized from NotI linearized CS2-fsta [90], CS2GDF6 [91], and CS3+mt-meis1 [38] templates, respectively, using the SP6 mMessage Machine kit (Applied Biosystems/Ambion, Austin, TX, USA) and purified using Microcon YM-50 columns (Millipore, Billerica, MA, USA). Embryos were injected at the one-cell stage with $10 \mathrm{pg}$ of GDF6 mRNA, $100 \mathrm{pg}$ of myc-meis 1 mRNA or $200 \mathrm{pg}$ of $f$ sta mRNA. Inhibition of Fgf signalling was done using PD173074 (Stemgent, Cambridge, MA, USA), a small molecule ATP-competitive inhibitor of FgfRs [92]. Wild-type and meis1 morphant embryos were incubated in a $50 \mu \mathrm{M}$ solution of PD173074 or $0.5 \%$ dimethyl sulfoxide (DMSO) control between the stages of $90 \%$ epiboly and seven somites. The embryos were removed from the treatment dishes, washed three times in embryo media, and grown at $28.5^{\circ} \mathrm{C}$ until fixation at the 28 hpf stage.

\section{mRNA in situ hybridization}

mRNA in situ hybridizations were performed essentially as described [93] with the following modifications. Antisense DIG-labelled probes were prepared either from a linearized plasmid template containing a gene-specific insert, or from a gene-specific PCR product containing either a T3 or T7 RNA polymerase site. In either case, each $20 \mu \mathrm{l}$ probe synthesis reaction included 200 to 400 ng of template, $2 \mu \mathrm{l}$ of $10 \times$ transcription buffer (Roche, Indianapolis, IN, USA), $2 \mu \mathrm{l} 10 \times$ DIG RNA labelling mix (Roche), 20 units $(0.5 \mu \mathrm{l})$ RNAsein (Promega, Madison, WI, USA), 20 units $(1 \mu \mathrm{l})$ of either T3 or T7 RNA 
polymerase (Roche), and RNase-free water up to $20 \mu \mathrm{l}$. Reactions were performed for 2 hours at $37^{\circ} \mathrm{C}$, with another 20 units of the appropriate RNA polymerase was added midway through the incubation. Following a 10 -minute DNase treatment at $37^{\circ} \mathrm{C}$, reactions were purified using SigmaSpin Post-Reaction Clean-Up Columns (Sigma-Aldrich) following the manufacturer's protocol. RNAlater (10 $\mu \mathrm{l}$; Sigma-Aldrich) was added to the flowthrough and the resultant probe was diluted 1:300 in hybridization solution and stored at $-20^{\circ} \mathrm{C}$. All steps of the protocol involving embryos were performed in 1.7 $\mathrm{ml}$ microfuge tubes. Pre-hybridization, hybridization, and wash steps were carried out in a $65^{\circ} \mathrm{C}$ waterbath. The $65^{\circ} \mathrm{C}$ washes were done as follows: $1 \times 5$ minutes for each of three solutions - 66\% hybridization solution/ $33 \% 2 \times$ SSC, $33 \%$ hybridization solution/66\% $2 \times$ SSC, and $100 \% 2 \times$ SSC/0.1\% Tween-20; high stringency washes were done for $1 \times 20$ minutes in $0.2 \times \mathrm{SSC} / 0.1 \%$ Tween- 20 and $2 \times 20$ minutes in $0.1 \times$ SSC/0.1\% Tween20. At room temperature, $1 \times 5$ minute washes were done with the following solutions: $66 \% 0.2 \times \mathrm{SSC} / 33 \%$ phosphate-buffered saline Tween-20 (PBST); 33\% 0.2× SSC/66\% PBST; 100\% PBST. Embryos were incubated for at least 2 hours in blocking solution and then incubated overnight at $4^{\circ} \mathrm{C}$ in a 1:5,000 dilution of sheep anti-DIG-AP FAB fragments (Roche) in blocking solution. Embryos were washed $5 \times 15$ minutes in PBST at room temperature to remove the antibody. The colouration reaction was performed using either the standard NBT/BCIP reagents dissolved in Alkaline Tris colouration buffer, or with BM Purple (Roche). For BM Purple colouration, embryos were rinsed twice briefly with water following the PBST washes to remove salt before the addition of $500 \mu \mathrm{l}$ of BM Purple colouration solution. To photograph the embryos, the yolk was manually removed and the embryos were equilibrated in 50\% and $70 \%$ glycerol solutions before being mounted. Embryos were photographed on a Zeiss AxioImager.Z1 scope with an Axiocam $\mathrm{HRm}$ camera with RGB filters. Embryos still on the yolk were photographed using a Zeiss Discovery.V8 stereoscope fitted with a QImaging micropublisher camera. All figures were assembled in Photoshop.

\section{Retinal ganglion cell labelling}

To analyze RGC axon mapping, axons were labelled with two lipophilic dyes (DiI, 1,1', di-octadecyl-3,3,3'3'tetramethylindocarbocyanine perchlorate; $\mathrm{DiO}, 3,3$ '-dioladecyloxacarbocyanine perchlorate) and their termination zones visualized using a Leica TCS-SP2 confocal microscope. DiI was dissolved in dimethylformamide at a concentration of $25 \mathrm{mg} / \mathrm{ml}$, while $\mathrm{DiO}$ was dissolved in chloroform at a concentration of $25 \mathrm{mg} / \mathrm{ml}$. For visualization of nuclei, embryos were incubated in
Hoechst 33258 stain (Invitrogen, Carlsbad, CA, USA) at $2.5 \mu \mathrm{g} / \mathrm{ml}$ in $\mathrm{PBS} / 0.0005 \%$ Tween-20) overnight at $28.5^{\circ} \mathrm{C}$. Efforts were made to inject a lower volume of dye into meis 1 morphants to account for their reduced eye size. To ensure that any overlap in the RGC termination zones we observed was not due to dye bleeding in the retina, labelled eyes were imaged to confirm the accuracy of the injections, and any embryos that did not have distinct red and green RGC axon tracts leaving the retina were excluded from further analysis.

\section{Immunohistochemistry}

For immunohistochemistry, the following primary antibodies and dilutions were used: anti-Meis1 P2A6-1 mouse monoclonal 1:5 [94]; anti-Phospho-Smad1/5/8 rabbit polyclonal 1:200 (Cell Signaling, Danvers, MA, USA); 1:500 anti-acetylated tubulin 6-11B-1 mouse monoclonal (Sigma-Aldrich). Secondary antibodies were either anti-mouse or anti-rabbit Alexa Fluor 488 (Invitrogen) diluted to 1:1,000. For the anti-Meis1 P2A6-1 and anti-Phospho-Smad1/5/8 immunos, standard $4 \%$ paraformaldehyde fixation and $10 \mu \mathrm{g} / \mathrm{ml}$ protK permeabilization protocols were used. The antibodies were diluted in $1 \times \mathrm{PBS} / 0.1 \%$ Triton- $\mathrm{X} / 1 \%$ bovine serum albu$\min / 10 \%$ goat serum blocking solution. For the acetylated tubulin stains, embryos were fixed overnight at $4^{\circ} \mathrm{C}$ in Dent's fixative (80\% methanol/20\% DMSO), gradually rehydrated, washed $3 \times 5$ minutes in $1 \times \mathrm{PBS} /$ $0.5 \%$ Tween-20, and blocked in $1 \times \mathrm{PBS} / 0.5 \%$ Tween-20/ $1 \% \mathrm{DMSO} / 1 \%$ bovine serum albumin/10\% goat serum. To mark nuclei, Hoechst 33258 (Invitrogen) at a concentration of $10 \mu \mathrm{g} / \mathrm{ml}$ was included in the overnight secondary antibody incubation step. All images were taken on either a Leica TCS-SP2 or a Zeiss LSM 510 confocal microscope. Z-projections were made in ImageJ and figures assembled in Photoshop.

\section{Gene expression profiling and quantification of tectal neuropil size}

The method of profiling of retinal mRNA in situ hybridizations was based on that described by Picker and Brand [27] with the following modifications. The mRNA in situ hybridization data used for quantification were all from a single round of morpholino injections and/or pharmaceutical treatments in order to control for variability in experiment-to-experiment differences in mRNA in situ staining intensity. Inverted grayscale images of dissected, flat-mounted retinas were prepared and oriented in Photoshop. The images were imported to ImageJ for pixel intensity analysis using the Oval profile plugin. Using the 'Along Oval' analysis mode, the pixel intensity was determined for 360 points around the circumference of the eye and these values were exported to Microsoft Excel for analysis and graphing. Two series 
of measurements were made per eye: one proximal to the lens and the other more distal. These two series were averaged to arrive at a single $360^{\circ}$ series of pixel intensities per eye. Using these averaged values, the nasal $(\mathrm{n})$ and temporal $(\mathrm{t})$ positions (in degrees) where pixel intensity fell to the halfway point between its minimum and maximum values $\left(\mathrm{nmax} / 2^{\circ}\right.$ and $\left.\mathrm{tmax} / 2^{\circ}\right)$ were determined for each eye. For the vax2 and ephb2 probes, the ventro-nasal and ventro-temporal regions (separated by the choroid fissure) were treated as separate domains, each with their own maximum pixel intensity value. For each in situ probe, the means of the wild-type $n \max / 2^{\circ}$ and/or tmax $/ 2^{\circ}$ were compared to the corresponding means for the meis1 morphant eyes using an unpaired, two-tailed $t$-test using a $P$-value of 0.01 as the cutoff for significance. The resulting mean $\mathrm{nmax} / 2^{\circ}$ and $\mathrm{tmax} / 2^{\circ}$ values were graphed using the Doughnut chart in Excel. The number of eyes used for each analysis along with the mean $n \max / 2^{\circ}$ and/or tmax $/ 2^{\circ}$ values ( \pm one standard deviation) are provided in the tables accompanying the graphs.

To quantify tectal neuropil area in wild-type and meis 1 morphant embryos, images of Hoechst 33258 stained 5dpf embryos were analyzed in ImageJ. The nuclei-free area of the neuropil were selected freehand and the pixel area was calculated using the Measure function. Measurements were compiled and graphed in Excel and the mean area values for wild-type and meis1 morphant embryos were compared using an unpaired, two-tailed $t$-test.

\section{Additional material}

Additional file 1: Two independent meis1 morpholinos result in similar phenotypes. (A-D) Two independent meis1 translation blocking morpholinos effectively knockdown Meis1 protein, as shown by whole mount immunohistochemistry using a Meis1 monoclonal antibody. Hoechst 33258 stain marks the nuclei. (E-H) The meis1 non-overlapping (NOL) morpholino gives similar phenotypes as the ATG-morpholino (compare with Figure 5A-D and Figure 6F, G). meis $1 \mathrm{NOL}$ morphants exhibit reduced foxd 1 expression in the presumptive temporal retina $(n=$ 27/29) (E, F), and upregulated fsta expression in the eye at $13 \mathrm{hpf}(n=$ 19/19) $(G, H)$. Dotted lines outline the optic vesicle. Views are dorsal with anterior to the left.

Additional file 2: Meis1-knockdown does not affect patterning of the midbrain-hindbrain boundary. (A-F) mRNA in situ hybridization for midbrain-hindbrain boundary (MHB) markers fgf8a (A, B), eng2a (C, D) and pax2a (E, F) in 32-hpf wild-type and meis1 morphant embryos. Arrows indicate the relevant gene expression domain at the MHB. The insets in $(E, F)$ are representative dissected eyes showing an upregulation of pax2a staining in the optic stalk of meis1 morphants $(n=18 / 18)$. Embryos are co-stained with the hindbrain $\mathrm{r} 3$ and $\mathrm{r} 5$ marker egr 26 . Embryos are shown in lateral view with dorsal up and anterior to the left, and the dissected retinas are oriented with dorsal up and nasal to the left.

Additional file 3: meis1 and smad1 expression in the early optic vesicle. (A, B) mRNA in situ hybridizations for meis 1 (A) and smad1 (B) in 10.5-hpf wild-type embryos. The dotted circles indicate the eye fields. Views are lateral with anterior on the top. (C, D) Transverse sections of wild-type 13-hpf optic vesicles stained for Meis1 protein (C) and smad1 mRNA (D). Note that (C) is the same as shown in Figure 1D. The dotted lines outline the optic vesicle and neural tube. Sections are oriented with dorsal at the top.

Additional file 4: Morpholino-insensitive myc-meis1 RNA can rescue the smad 1 and fsta expression defects in meis 1 morphants. (A-H) mRNA in situ hybridizations for smad1 (A-D) and fsta (E-H) in wild-type ( $\mathrm{A}, \mathrm{E})$, myc-meis1 RNA (B, F), meis1 morphant ( $\mathrm{C}, \mathrm{G})$ and myc-meis1 RNA/ meis1 morphant embryos at $14 \mathrm{hpf}$. All embryos are shown in dorsal view with anterior to the left.

Additional file 5: gdf6a morphants have normal smad1 and fsta expression at 13 hpf. (A-D) mRNA in situ hybridizations for smad1 (A, B) and fsta $(C, D)$ in wild-type $(A, C)$ and gdf6a morphant $(B, D)$ embryos at $13 \mathrm{hpf}$. Dotted lines outline the optic vesicle. Views are dorsal with anterior to the left.

Additional file 6: smad5 expression is normal in meis 1 morphants. (A-D) mRNA in situ hybridization for smad5 on wild-type (A, B) and meis 1 morphant (C, D) embryos at 15 hpf. (A, C) Lateral views with anterior up; $(B, D)$ dorsal views with anterior to the left.

Additional file 7: The temporal expression domains of epha7 and epha4b are reduced in meis 1 morphants. (A, B) mRNA in situ hybridization (ISH) for epha7 on wild-type (A) and meis1 morphant (B) embryos at $16 \mathrm{hpf}$. Arrows indicate the expression of epha7 in the presumptive temporal retina. Embryos are shown in dorsal view with anterior to the left. (C-F) mRNA ISH for the temporal markers epha7 (C, D) and epha4b (E, F) in dissected, flat-mounted eyes from 26- to 28-hpf wild-type and meis 1 morphant embryos. Arrows indicate the dorsal extent of gene expression. Representative dissected eyes are shown. Legend for retinal axial orientation: D, dorsal; V, ventral; N, nasal; T, temporal.

Additional file 8: The RGC axon stalling phenotype in meis1 morphants. (A, B) Dorsal-ventral (A) and nasal-temporal (B) RGC axon stalling phenotypes in meis 1 morphants. Arrows indicate the stalled RGC axons labelled with fluorescent lipophilic dyes Dil (red) and DiO (green). Hoechst 33258 (blue) marks nuclei. All views are dorsal with anterior to the left. Legend for axial position in the tectum: M, medial; L, lateral; A, anterior; $P$, posterior.

\section{Abbreviations}

Bmp: Bone morphogenetic protein; DMSO: dimethyl sulfoxide; DV: dorsalventral; efn: ephrin; Fgf: Fibroblast growth factor; FgfR: Fgf receptor; Fsta: follistatin a; Gdf: Growth differentiation factor; hpf: hours post-fertilization; NOL: non-overlapping; NT: nasal-temporal; PBST: phosphate-buffered saline Tween-20; RGC: retinal ganglion cell.

\section{Acknowledgements}

Thank you to Christine and Bernard Thisse for the gift of the fsta expression construct. Also, thank you to Todd Evans for providing smad5 morpholino that was used in some preliminary experiments, and to Michael Tsang for his helpful advice. Thanks to Aleah McCorry for taking excellent care of the fish, to Laura Pillay for commenting on the manuscript, to Danielle French for her help with imaging, and to Christine Erickson for her graphical assistance. AJW is a recipient of a Canada Research Chair. This work was supported by NSERC (AJW, TE, CRF), The Alberta Ingenuity Foundation (TE), and the Alberta Heritage Foundation for Medical Research (CRF).

\section{Author details}

'Department of Biological Sciences, University of Alberta, CW405, Biological Sciences Bldg, Edmonton T6G 2E9, Canada. ${ }^{2}$ Centre for Neuroscience, University of Alberta, CW405, Biological Sciences Bldg, Edmonton T6G 2E9, Canada. ${ }^{3}$ Women and Children's Health Research Institute, University of Alberta, CW405, Biological Sciences Bldg, Edmonton T6G 2E9, Canada.

\section{Authors' contributions}

TE performed all experiments except for the ganglion cell axon labeling that was done by CRF. TE and AJW conceived of the study, designed the experiments and analyzed the data. TE drafted the manuscript with editorial assistance from CRF and AJW. All authors read and approved the final manuscript. 


\section{Competing interests}

The authors declare that they have no competing interests.

Received: 26 November 2009 Accepted: 1 September 2010

Published: 1 September 2010

\section{References}

1. Scicolone G, Ortalli AL, Carri NG: Key roles of Ephs and ephrins in retinotectal topographic map formation. Brain Res Bull 2009, 79:227-247.

2. Lemke $G$, Reber $M$ : Retinotectal mapping: new insights from molecular genetics. Annu Rev Cell Dev Biol 2005, 21:551-580.

3. McLaughlin T, Hindges R, O'Leary DD: Regulation of axial patterning of the retina and its topographic mapping in the brain. Curr Opin Neurobiol 2003, 13:57-69.

4. Harada T, Harada C, Parada LF: Molecular regulation of visual system development: more than meets the eye. Genes Dev 2007, 21:367-378.

5. Gosse NJ, Baier H: An essential role for Radar (Gdf6a) in inducing dorsal fate in the zebrafish retina. Proc Natl Acad Sci USA 2009, 106:2236-2241.

6. French CR, Erickson T, French DV, Pilgrim DB, Waskiewicz AJ: Gdf6a is required for the initiation of dorsal-ventral retinal patterning and lens development. Dev Biol 2009, 333:37-47.

7. Koshiba-Takeuchi K, Takeuchi JK, Matsumoto K, Momose T, Uno K, Hoepker V, Ogura K, Takahashi N, Nakamura H, Yasuda K, Ogura T: Tbx5 and the retinotectum projection. Science 2000, 287:134-137.

8. Behesti H, Holt JK, Sowden JC: The level of BMP4 signaling is critical for the regulation of distinct T-box gene expression domains and growth along the dorso-ventral axis of the optic cup. BMC Dev Biol 2006, 6:62.

9. Zhou CJ, Molotkov A, Song L, Li Y, Pleasure DE, Pleasure SJ, Wang YZ: Ocular coloboma and dorsoventral neuroretinal patterning defects in Lrp6 mutant eyes. Dev Dyn 2008, 237:3681-3689.

10. Veien ES, Rosenthal JS, Kruse-Bend RC, Chien CB, Dorsky Rl: Canonical Wnt signaling is required for the maintenance of dorsal retinal identity. Development 2008, 135:4101-4111.

11. Take-uchi M, Clarke JD, Wilson SW: Hedgehog signalling maintains the optic stalk-retinal interface through the regulation of Vax gene activity. Development 2003, 130:955-968.

12. Zhang XM, Yang XJ: Temporal and spatial effects of Sonic hedgehog signaling in chick eye morphogenesis. Dev Biol 2001, 233:271-290.

13. Lupo G, Liu Y, Qiu R, Chandraratna RAS, Barsacchi G, He R-Q, Harris WA: Dorsoventral patterning of the Xenopus eye: a collaboration of Retinoid, Hedgehog and FGF receptor signaling. Development 2005, 132:1737-1748.

14. Barbieri AM, Broccoli V, Bovolenta P, Alfano G, Marchitiello A, Mocchetti C, Crippa L, Bulfone A, Marigo V, Ballabio A, Banfi S: Vax2 inactivation in mouse determines alteration of the eye dorsal-ventral axis, misrouting of the optic fibres and eye coloboma. Development 2002, 129:805-813.

15. Schulte D, Furukawa T, Peters MA, Kozak CA, Cepko CL: Misexpression of the Emx-related homeobox genes cVax and mVax2 ventralizes the retina and perturbs the retinotectal map. Neuron 1999, 24:541-553.

16. Mui SH, Hindges R, O'Leary DD, Lemke G, Bertuzzi S: The homeodomain protein Vax2 patterns the dorsoventral and nasotemporal axes of the eye. Development 2002, 129:797-804.

17. Mui SH, Kim JW, Lemke G, Bertuzzi S: Vax genes ventralize the embryonic eye. Genes Dev 2005, 19:1249-1259.

18. Mann F, Ray S, Harris W, Holt C: Topographic mapping in dorsoventral axis of the Xenopus retinotectal system depends on signaling through ephrin-B ligands. Neuron 2002, 35:461-473.

19. Hindges R, McLaughlin T, Genoud N, Henkemeyer M, O'Leary DD: EphB forward signaling controls directional branch extension and arborization required for dorsal-ventral retinotopic mapping. Neuron 2002, 35:475-487.

20. Takahashi H, Sakuta H, Shintani T, Noda M: Functional mode of FoxD1/ CBF2 for the establishment of temporal retinal specificity in the developing chick retina. Dev Biol 2009, 331:300-310.

21. Takahashi H, Shintani T, Sakuta H, Noda M: CBF1 controls the retinotectal topographical map along the anteroposterior axis through multiple mechanisms. Development 2003, 130:5203-5215.

22. Hatini V, Tao W, Lai E: Expression of winged helix genes, BF-1 and BF-2, define adjacent domains within the developing forebrain and retina. $J$ Neurobiol 1994, 25:1293-1309.

23. Feldheim DA, Kim YI, Bergemann AD, Frisen J, Barbacid M, Flanagan JG: Genetic analysis of ephrin-A2 and ephrin-A5 shows their requirement in multiple aspects of retinocollicular mapping. Neuron 2000, 25:563-574.
24. Feldheim DA, Nakamoto M, Osterfield M, Gale NW, DeChiara TM, Rohatgi R, Yancopoulos GD, Flanagan JG: Loss-of-function analysis of EphA receptors in retinotectal mapping. J Neurosci 2004, 24:2542-2550.

25. Hornberger MR, Dutting D, Ciossek T, Yamada T, Handwerker C, Lang S, Weth F, Huf J, Wessel R, Logan C, Tanaka H, Drescher U: Modulation of EphA receptor function by coexpressed ephrinA ligands on retinal ganglion cell axons. Neuron 1999, 22:731-742.

26. Nakayama Y, Miyake A, Nakagawa Y, Mido T, Yoshikawa M, Konishi M, Itoh N: Fgf19 is required for zebrafish lens and retina development. Dev Biol 2008, 313:752-766.

27. Picker $\mathrm{A}, \mathrm{Brand} \mathrm{M}$ : Fgf signals from a novel signaling center determine axial patterning of the prospective neural retina. Development 2005, 132:4951-4962.

28. Picker A, Cavodeassi F, Machate A, Bernauer S, Hans S, Abe G, Kawakami K, Wilson SW, Brand M: Dynamic coupling of pattern formation and morphogenesis in the developing vertebrate retina. PLoS Biol 2009, 7 : e1000214.

29. Rashid T, Upton AL, Blentic A, Ciossek T, Knoll B, Thompson ID, Drescher U: Opposing gradients of ephrin-As and EphA7 in the superior colliculus are essential for topographic mapping in the mammalian visual system. Neuron 2005, 47:57-69.

30. Goodhill GJ, Richards LJ: Retinotectal maps: molecules, models and misplaced data. Trends Neurosci 1999, 22:529-534.

31. Cheng HJ, Nakamoto M, Bergemann AD, Flanagan JG: Complementary gradients in expression and binding of ELF-1 and Mek4 in development of the topographic retinotectal projection map. Cell 1995, 82:371-381.

32. Nakamoto M, Cheng HJ, Friedman GC, McLaughlin T, Hansen MJ, Yoon CH, O'Leary DD, Flanagan JG: Topographically specific effects of ELF-1 on retinal axon guidance in vitro and retinal axon mapping in vivo. Cell 1996, 86:755-766.

33. Gosse NJ, Nevin LM, Baier H: Retinotopic order in the absence of axon competition. Nature 2008, 452:892-895.

34. Cooke JE, Kemp HA, Moens CB: EphA4 is required for cell adhesion and rhombomere-boundary formation in the zebrafish. Curr Biol 2005, 15:536-542.

35. Kemp HA, Cooke JE, Moens CB: EphA4 and EfnB2a maintain rhombomere coherence by independently regulating intercalation of progenitor cells in the zebrafish neural keel. Dev Biol 2009, 327:313-326.

36. Xu Q, Mellitzer G, Robinson V, Wilkinson DG: In vivo cell sorting in complementary segmental domains mediated by Eph receptors and ephrins. Nature 1999, 399:267-271.

37. Choe SK, Vlachakis N, Sagerstrom CG: Meis family proteins are required for hindbrain development in the zebrafish. Development 2002, 129:585-595

38. Waskiewicz AJ, Rikhof HA, Hernandez RE, Moens CB: Zebrafish Meis functions to stabilize $\mathrm{Pbx}$ proteins and regulate hindbrain patterning. Development 2001, 128:4139-4151.

39. Waskiewicz AJ, Rikhof HA, Moens CB: Eliminating zebrafish pbx proteins reveals a hindbrain ground state. Dev Cell 2002, 3:723-733.

40. Deflorian G, Tiso N, Ferretti E, Meyer D, Blasi F, Bortolussi M, Argenton F: Prep1.1 has essential genetic functions in hindbrain development and cranial neural crest cell differentiation. Development 2004, 131:613-627.

41. Moens CB, Selleri L: Hox cofactors in vertebrate development. Dev Biol 2006, 291:193-206.

42. Maves L, Waskiewicz AJ, Paul B, Cao Y, Tyler A, Moens CB, Tapscott SJ: Pbx homeodomain proteins direct Myod activity to promote fast-muscle differentiation. Development 2007, 134:3371-3382.

43. Erickson T, Scholpp S, Brand M, Moens CB, Waskiewicz AJ: Pbx proteins cooperate with Engrailed to pattern the midbrain-hindbrain and diencephalic-mesencephalic boundaries. Dev Biol 2007, 301:504-517.

44. French CR, Erickson T, Callander D, Berry KM, Koss R, Hagey DW, Stout J, Wuennenberg-Stapleton K, Ngai J, Moens CB, Waskiewicz AJ: Pbx homeodomain proteins pattern both the zebrafish retina and tectum. BMC Dev Biol 2007, 7:85.

45. Zhang X, Friedman A, Heaney S, Purcell P, Maas RL: Meis homeoproteins directly regulate Pax6 during vertebrate lens morphogenesis. Genes Dev 2002, 16:2097-2107.

46. Maves $L$, Tyler A, Moens $C B$, Tapscott SJ: Pbx acts with Hand2 in early myocardial differentiation. Dev Biol 2009, 333:409-418

47. Bessa J, Tavares MJ, Santos J, Kikuta H, Laplante M, Becker TS, GomezSkarmeta JL, Casares F: meis1 regulates cyclin D1 and c-myc expression, 
and controls the proliferation of the multipotent cells in the early developing zebrafish eye. Development 2008, 135:799-803.

48. Heine P, Dohle E, Bumsted-O'Brien K, Engelkamp D, Schulte D: Evidence for an evolutionary conserved role of homothorax/Meis $1 / 2$ during vertebrate retina development. Development 2008, 135:805-811.

49. Hisa T, Spence SE, Rachel RA, Fujita M, Nakamura T, Ward JM, DevorHenneman DE, Saiki Y, Kutsuna H, Tessarollo L, Jenkins NA, Copeland NG: Hematopoietic, angiogenic and eye defects in Meis1 mutant animals. EMBO J 2004, 23:450-459.

50. Bessa J, Gebelein B, Pichaud F, Casares F, Mann RS: Combinatorial control of Drosophila eye development by eyeless, homothorax, and teashirt. Genes Dev 2002, 16:2415-2427.

51. Pai $C Y$, Kuo $T S$, Jaw $T$, Kurant $E$, Chen $C T$, Bessarab DA, Salzberg A, Sun $Y H$ : The Homothorax homeoprotein activates the nuclear localization of another homeoprotein, extradenticle, and suppresses eye development in Drosophila. Genes Dev 1998, 12:435-446.

52. Huang H, Rastegar M, Bodner C, Goh SL, Rambaldi I, Featherstone M: MEIS C termini harbor transcriptional activation domains that respond to cell signaling. J Biol Chem 2005, 280:10119-10127.

53. Shen WF, Montgomery JC, Rozenfeld S, Moskow JJ, Lawrence HJ, Buchberg AM, Largman C: AbdB-like Hox proteins stabilize DNA binding by the Meis1 homeodomain proteins. Mol Cell Biol 1997, 17:6448-6458

54. Chang CP, Jacobs Y, Nakamura T, Jenkins NA, Copeland NG, Cleary ML: Meis proteins are major in vivo DNA binding partners for wild-type but not chimeric Pbx proteins. Mol Cell Biol 1997, 17:5679-5687.

55. Chen J, Ruley HE: An enhancer element in the EphA2 (Eck) gene sufficient for rhombomere-specific expression is activated by HOXA1 and HOXB1 homeobox proteins. J Biol Chem 1998, 273:24670-24675.

56. Shim S, Kim Y, Shin J, Kim J, Park S: Regulation of EphA8 gene expression by TALE homeobox transcription factors during development of the mesencephalon. Mol Cell Biol 2007, 27:1614-1630.

57. Sohl M, Lanner F, Farnebo F: Characterization of the murine Ephrin-B2 promoter. Gene 2009, 437:54-59.

58. Theil T, Frain M, Gilardi-Hebenstreit P, Flenniken A, Charnay P, Wilkinson DG: Segmental expression of the EphA4 (Sek-1) receptor tyrosine kinase in the hindbrain is under direct transcriptional control of Krox-20. Development 1998, 125:443-452.

59. Agoston Z, Schulte D: Meis2 competes with the Groucho co-repressor Tle4 for binding to Otx2 and specifies tectal fate without induction of a secondary midbrain-hindbrain boundary organizer. Development 2009, 136:3311-3322.

60. Stuermer CA: Retinotopic organization of the developing retinotectal projection in the zebrafish embryo. J Neurosci 1988, 8:4513-4530.

61. Arnold SJ, Maretto S, Islam A, Bikoff EK, Robertson EJ: Dose-dependent Smad1, Smad5 and Smad8 signaling in the early mouse embryo. Dev Biol 2006, 296:104.

62. Pangas SA, Li X, Umans L, Zwijsen A, Huylebroeck D, Gutierrez C, Wang D, Martin JF, Jamin SP, Behringer RR, Robertson EJ, Matzuk MM: Conditional deletion of Smad1 and Smad5 in somatic cells of male and female gonads leads to metastatic tumor development in mice. Mol Cell Biol 2008, 28:248-257.

63. Retting KN, Song B, Yoon BS, Lyons KM: BMP canonical Smad signaling through Smad1 and Smad5 is required for endochondral bone formation. Development 2009, 136:1093-1104.

64. Amthor H, Christ B, Rashid-Doubell F, Kemp CF, Lang E, Patel K: Follistatin regulates bone morphogenetic protein-7 (BMP-7) activity to stimulate embryonic muscle growth. Dev Biol 2002, 243:115-127.

65. Fainsod A, Deissler K, Yelin R, Marom K, Epstein M, Pillemer G, Steinbeisser $\mathrm{H}$, Blum M: The dorsalizing and neural inducing gene follistatin is an antagonist of BMP-4. Mech Dev 1997, 63:39-50.

66. lemura S, Yamamoto TS, Takagi C, Uchiyama H, Natsume T, Shimasaki S, Sugino $H$, Ueno N: Direct binding of follistatin to a complex of bonemorphogenetic protein and its receptor inhibits ventral and epidermal cell fates in early Xenopus embryo. Proc Natl Acad Sci USA 1998, 95:9337-9342

67. Chang C, Hemmati-Brivanlou A: Xenopus GDF6, a new antagonist of noggin and a partner of BMPs. Development 1999, 126:3347-3357.

68. Furthauer M, Lin W, Ang SL, Thisse B, Thisse C: Sef is a feedback-induced antagonist of Ras/MAPK-mediated FGF signalling. Nat Cell Biol 2002, 4:170-174
69. Tsang M, Friesel R, Kudoh T, Dawid IB: Identification of Sef, a novel modulator of FGF signalling. Nat Cell Biol 2002, 4:165-169.

70. Molina G, Watkins S, Tsang M: Generation of FGF reporter transgenic zebrafish and their utility in chemical screens. BMC Dev Biol 2007, 7:62.

71. Li C, Scott DA, Hatch E, Tian X, Mansour SL: Dusp6 (Mkp3) is a negative feedback regulator of FGF-stimulated ERK signaling during mouse development. Development 2007, 134:167-176.

72. Vlachakis N, Choe SK, Sagerstrom CG: Meis3 synergizes with Pbx4 and Hoxb1b in promoting hindbrain fates in the zebrafish. Development 2001, 128:1299-1312

73. Sakuta H, Takahashi H, Shintani T, Etani K, Aoshima A, Noda M: Role of bone morphogenic protein 2 in retinal patterning and retinotectal projection. J Neurosci 2006, 26:10868-10878.

74. Plas DT, Dhande OS, Lopez JE, Murali D, Thaller C, Henkemeyer M, Furuta Y, Overbeek P, Crair MC: Bone morphogenetic proteins, eye patterning, and retinocollicular map formation in the mouse. J Neurosci 2008, 28:7057-7067.

75. Sakuta H, Suzuki R, Takahashi H, Kato A, Shintani T, lemura S, Yamamoto TS, Ueno N, Noda M: Ventroptin: a BMP-4 antagonist expressed in a doublegradient pattern in the retina. Science 2001, 293:111-115.

76. Murali D, Yoshikawa S, Corrigan RR, Plas DJ, Crair MC, Oliver G, Lyons KM, Mishina $Y$, Furuta $Y$ : Distinct developmental programs require different levels of Bmp signaling during mouse retinal development. Development 2005, 132:913-923

77. Choe S-K, Lu P, Nakamura M, Lee J, Sagerstöm CG: Meis cofactors control HDAC and CBP accessibility at Hox-regulated promoters during zebrafish embryogenesis. Dev Cell 2009, 17:561-567.

78. Goh SL, Looi Y, Shen H, Fang J, Bodner C, Houle M, Ng AC, Screaton RA, Featherstone M: Transcriptional activation by MEIS1A in response to protein kinase $A$ signaling requires the transducers of regulated CREB family of CREB co-activators. J Biol Chem 2009, 284:18904-18912.

79. Mann RS, Lelli KM, Joshi R: Hox specificity unique roles for cofactors and collaborators. Curr Top Dev Biol 2009, 88:63-101.

80. Freudenberg JA, Chen WT: Induction of Smad1 by MT1-MMP contributes to tumor growth. Int J Cancer 2007, 121:966-977.

81. Sun Y, Fan J, Shen H, Li P, Cattini P, Gong Y: Cloning and promoter activity of rat Smad1 $5^{\prime}$-flanking region in rat hepatic stellate cells. Mol Cell Biochem 2007, 304:227-234

82. Dick A, Meier A, Hammerschmidt M: Smad1 and Smad5 have distinct roles during dorsoventral patterning of the zebrafish embryo. Dev Dyn 1999, 216:285-298.

83. McReynolds L, Gupta S, Figueroa ME, Mullins MC, Evans T: Smad1 and Smad5 differentially regulate embryonic hematopoiesis. Blood 2007, 110:3881-3890.

84. Li Z, Joseph NM, Easter SS Jr: The morphogenesis of the zebrafish eye, including a fate map of the optic vesicle. Dev Dyn 2000, 218:175-188.

85. Schmitt EA, Dowling JE: Early eye morphogenesis in the zebrafish, Brachydanio rerio. J Comp Neurol 1994, 344:532-542.

86. Cooke JE, Moens CB: Boundary formation in the hindbrain: Eph only it were simple. Trends Neurosci 2002, 25:260-267.

87. Westerfield M: In The Zebrafish Book. A Guide for the Laboratory Use of Zebrafish (Danio rerio). Edited by: Eugene OR. Univ. of Oregon Press; , 4 2000:

88. Kimmel CB, Ballard WW, Kimmel SR, Ullmann B, Schilling TF: Stages of embryonic development of the zebrafish. Dev Dyn 1995, 203:253-310.

89. Asai-Coakwell M, French CR, Berry KM, Ye M, Koss R, Somerville M, Mueller R, van Heyningen V, Waskiewicz AJ, Lehmann OJ: GDF6, a novel locus for a spectrum of ocular developmental anomalies. Am J Hum Genet 2007, 80:306-315.

90. Dal-Pra S, Furthauer M, Van-Celst J, Thisse B, Thisse C: Noggin1 and Follistatin-like2 function redundantly to Chordin to antagonize BMP activity. Dev Biol 2006, 298:514-526.

91. Asai-Coakwell M, French CR, Ye M, Garcha K, Bigot K, Perera AG, StaehlingHampton K, Mema SC, Chanda B, Mushegian A, Bamforth S, Doschak MR, Li G, Dobbs MB, Giampietro PF, Brooks BP, Vijayalakshmi P, Sauvé Y, Abitbol M, Sundaresan P, van Heyningen V, Pourquié O, Underhill TM, Waskiewicz AJ, Lehmann OJ: Incomplete penetrance and phenotypic variability characterize Gdf6-attributable oculo-skeletal phenotypes. Hum Mol Genet 2009, 18:1110-1121. 
92. Mohammadi M, Froum S, Hamby JM, Schroeder MC, Panek RL, Lu GH, Eliseenkova AV, Green D, Schlessinger J, Hubbard SR: Crystal structure of an angiogenesis inhibitor bound to the FGF receptor tyrosine kinase domain. EMBO J 1998, 17:5896-5904.

93. Thisse C, Thisse B: High-resolution in situ hybridization to whole-mount zebrafish embryos. Nat Protoc 2008, 3:59-69.

94. Pillay LM, Forrester AM, Erickson T, Berman JN, Waskiewicz AJ: The Hox cofactors Meis1 and $\mathrm{Pbx}$ act upstream of gata1 to regulate primitive hematopoiesis. Dev Biol 2010, 340:306-317.

doi:10.1186/1749-8104-5-22

Cite this article as: Erickson et al: Meis1 specifies positional information in the retina and tectum to organize the zebrafish visual system. Neural Development 2010 5:22.

\section{Submit your next manuscript to BioMed Central} and take full advantage of:

- Convenient online submission

- Thorough peer review

- No space constraints or color figure charges

- Immediate publication on acceptance

- Inclusion in PubMed, CAS, Scopus and Google Scholar

- Research which is freely available for redistribution

Submit your manuscript at www.biomedcentral.com/submit 